\title{
Chromophores from hexeneuronic acids (HexA): synthesis of model compounds and primary degradation intermediates
}

\author{
Thomas Rosenau (D) Antje Potthast - Nele Sophie Zwirchmayr • \\ Takashi Hosoya $\cdot$ Hubert Hettegger • Markus Bacher • Karin Krainz • \\ Yuko Yoneda · Thomas Dietz
}

Received: 9 April 2017 / Accepted: 1 July 2017/Published online: 13 July 2017

(C) The Author(s) 2017. This article is an open access publication

\begin{abstract}
Hexeneuronic acid (HexA) is formed under pulping conditions from 4-O-methyl-glucuronic acid residues in xylans by methanol elimination. It is usually removed by an acidic washing treatment (Astage) within the pulp bleaching sequence. Hexeneuronic acid has long been recognized as a source of color generation in pulps, but the chemical structure of the actual chromophoric compounds remained elusive. We report the synthesis of isotopically $\left({ }^{13} \mathrm{C}\right)$ labeled HexA model units carrying a label at any of the six carbon atoms. Confirming pertinent literature accounts, it is shown that HexA forms three primary
\end{abstract}

Chromophores in cellulosic materials. Part XV.

This work is dedicated to Dr. Hans-Ulrich Suess, formerly Degussa and Degussa-Evonik, who devoted his whole life to the understanding of chromophore formation in cellulosic pulps and bleaching phenomena.

T. Rosenau $(\bowtie) \cdot$ A. Potthast · N. S. Zwirchmayr .

T. Hosoya $\cdot$ H. Hettegger $\cdot$ M. Bacher

Division of Chemistry of Renewable Resources,

Department of Chemistry, BOKU University Vienna,

Muthgasse 18, 1190 Vienna, Austria

e-mail: thomas.rosenau@boku.ac.at

K. Krainz

Air Liquid GmbH, Sendnergasse 30, 2320 Schwechat, Austria

Y. Yoneda

College of Agriculture, Shizuoka University, Ohya 836,

Suruga-ku, Shizuoka 422-8529, Japan degradation intermediates, 2-furancarboxylic acid, 5-formyl-2-furancarboxylic acid, and formic acid, under mildly acidic conditions, and their formation mechanism is discussed. 2-Furancarboxylic acid is demonstrated to be deformylation product of 5-formyl-2-furancarboxylic acid. The three primary intermediates are colorless and do not represent chromophores themselves. Their mixture, upon thermal or acidic treatment, gives rise to the same chromophores that are also directly formed from HexA.

Keywords Cellulose $\cdot$ Pulp · Chromophores · Hexeneuronic acids · Bleaching · A-stage · Furan · Furancarboxylic acid $\cdot$ Ladder-type oligomers

T. Dietz

Evonik-Degussa, Rodenbacher Chaussee 4,

63457 Hanau-Wolfgang, Germany

T. Rosenau

Johan Gadolin Process Chemistry Centre, Åbo Akademi

University, Porthansgatan 3, $20500 \AA ̊$ Abo/Turku, Finland 


\section{Introduction}

The CRI method (chromophore release and identification) opened the way to isolate and identify welldefined chromophoric structures from cellulosic matrices, despite their very low concentration (Rosenau et al. 2004). This technique has been applied to different cellulosic materials, including cellulose I substrates (pulps, (Rosenau et al. 2007, 2008) bacterial cellulose, (Rosenau et al. 2014) cotton (Rosenau et al. 2011), cellulose II substrates (regenerated celluloses such as rayon or Lyocell fibers), (Adorjan et al. 2005; Rosenau et al. 2005) and cellulose derivatives (cellulose 2.5-acetates, cellulose 3-acetates) (Rosenau et al. 2005). In each case, different numbers of compounds (between 3 and 12 individual compounds) at different concentrations (between 4 and 42 ppm for the chromophore mixture) have been isolated. Making individual chromophoric structures known and rendering the compounds accessible to chemical, analytical, and bleaching studies can be seen as the main benefit of the method. With this basic knowledge at hand, industrial bleaching sequences can be optimized, discoloration treatments followed more easily, and destruction of chromophores optimized while at the same time keeping chemical usage and energy costs down, and accounts of this approach have been published.

So far, the CRI method has been applied to ligninfree-or at least lignin-poor-cellulosic materials as higher content of lignin would overwhelm the separation and identification capability of the technique (Korntner et al. 2015). The chromophores isolated so far thus resulted exclusively from cellulose, and their formation occurred either by oxidative "aging" (Potthast et al. 2005) with follow-up fragmentations/condensations or through side reactions of cellulose processing (Potthast et al. 2009), such as upon xanthogenation in rayon manufacture, dissolution in $\mathrm{N}$-methylmorpholine- $\mathrm{N}$-oxide in Lyocell production, or acetylation/deacetylation in cellulose acetate synthesis or acetic acid- based solvents (Potthast et al. 2002). However, since the CRI approach is quite general, it can not only be used to address cellulosederived chromophores, but aromatic and quinoid chromophores in polysaccharide matrices in general.

One of the most important of such non-cellulosederived chromophore sources is hexeneuronic acid (HexA), the term being used as shorthand for the 4-deoxy- $\beta$-L-threo-hex-4-enopyranosiduronic acid moiety. Within the series on chromophores in cellulosic materials, the present report and the subsequent parts will address the issue of chromophores from HexA, their formation mechanism, and their chemical behavior under standard bleaching conditions. As it was in the case of the cellulose-derived chromophores, the prime challenge was to identify the structures of the individual chromophoric compounds. This was done again with the help of model compounds and by comparison to independently synthesized, authentic samples. With the knowledge of the chemical structures at hand, the second step, a study of the compounds' destruction in bleaching attempts, is much facilitated as compared to situations when just general or vague structural elements are known or suspected.

Early research on the chemical behavior of hemicelluloses during the pulping process by Clayton suggested the formation of 4-deoxy- $\beta$-L-threo-hex-4enopyranosiduronic acid moieties taking place during alkaline treatment of wood chips for delignification at temperatures of up to $170{ }^{\circ} \mathrm{C}$ (Clayton 1963; Chakar et al. 2000). The proposed mechanism was $\beta$-elimination of methanol taking place at the 4-O-methyl-Dglucuronic acid residues of xylans, resulting in HexA (see Scheme 1). The resulting double bond is always placed regioselectively towards $\mathrm{C}-5$, but not $\mathrm{C}-3$, to enable the conjugated $\alpha, \beta$-unsaturated acid structure.

These results of early analytical studies (Clayton 1963) were further affirmed by Johansson and
Scheme 1 Alkalicatalyzed formation of HexA from glucuronoxylan by $\beta$-elemination of methanol during pulping. (Chakar et al. 2000)
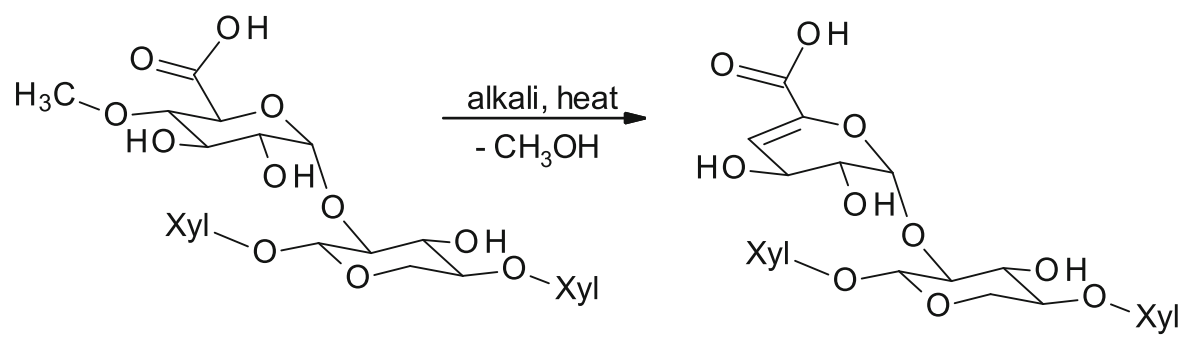
Samuelsson using dimeric model compounds (Johansson and Samuelson 1977). Acid treatments of HexA-containing pulps caused degradation of the proposed unsaturated uronic acids and only xylans and "tar" were found in the hydrolysate (Chakar et al. 2000; Johansson and Samuelson 1977; Teleman et al. 1995; Shimizu 1981). The application of a highly hemicellulose-specific enzymatic hydrolysis method to kraft pulps by Teleman et al. finally allowed definite identification of these acidic side groups on xylan (Teleman et al. 1995). After enzymatic degradation, acidic oligosaccharides were separated from uncharged components by anion exchange, further fractioned by SEC, and determined to be HexA mainly by NMR experiments. The knowledge on the formation of HexA and its suspected role in chromophore formation lead to an increase in the research efforts regarding its degradation. The bleaching research focused increasingly on the xylan carbohydrate fraction of wood and pulp, the origin of HexA. The contribution of HexA to decreased brightness in pulps, viz. its large influence on the kappa number, and its behavior during acid hydrolyses was thoroughly established (Li and Gellerstedt 1997; Clavijo et al. 2012). Acidic conditions, e.g. at $130{ }^{\circ} \mathrm{C}$ for $2-3 \mathrm{~h}$ with $0.05 \mathrm{M} \mathrm{H}_{2} \mathrm{SO}_{4}$, (Johansson and Samuelson 1977) or at 80-140 ${ }^{\circ} \mathrm{C}$ and $\mathrm{pH} 3.0-3.5$ for $2-5 \mathrm{~h}$, (Chakar et al. 2000; Clavijo et al. 2012) allowed removal of the HexA side groups, but also caused occurrence of furanoid primary products, e.g. 2-furancarboxylic acid and 5-formyl-2-furancarboxylic acid, which gave rise to unidentified chromophoric compounds (Clavijo et al. 2012; Teleman et al. 1996). In the following, the mechanism of HexA degradation and the structure of the resulting chromophores will be addressed in detail.

\section{Materials and methods}

\section{General}

Commercial chemicals were of the highest grade available and were used without further purification. Reagent grade solvents were used for all extractions and workup procedures. Distilled water was used for all aqueous extractions and for all aqueous solutions. $n$-Hexane, diethyl ether, ethyl acetate, and petroleum ether used in chromatography were distilled before use. All reactions involving non-aqueous conditions were conducted in oven-dried $\left(140{ }^{\circ} \mathrm{C}\right.$, overnight $)$ or flame-dried glassware under an inert argon or nitrogen atmosphere. TLC was performed using Merck silica gel $60 \mathrm{~F}_{254}$ pre-coated glass plates. Flash chromatography was performed using Baker silica gel $(40 \mu \mathrm{m}$ particle size). All products were purified to homogeneity by TLC/GC-MS analysis. The use of brine refers to saturated aqueous $\mathrm{NaCl}$ solution. All given yields refer to isolated, pure products. ${ }^{13} \mathrm{C}$-Labeled starting compounds were purchased from Omicron Biochemicals, Inc., South Bend, IN, USA, and from Euriso-Top GmbH, Saarbrücken, Germany.

NMR spectra were recorded at $400.13 \mathrm{MHz}$ for ${ }^{1} \mathrm{H}$ and at $100.62 \mathrm{MHz}$ for ${ }^{13} \mathrm{C}$ NMR at room temperature, in the perdeuterated solvents given. Chemical shifts, relative to tetramethylsilane (TMS) as the internal standard, are given in $\delta \mathrm{ppm}$ values, and coupling constants in $\mathrm{Hz} .{ }^{13} \mathrm{C}$ peaks were assigned by means of high-resolved $1 \mathrm{D}-{ }^{13} \mathrm{C}$, APT, HSQC and HMBC spectra. Through experiments without ${ }^{1} \mathrm{H}$-decoupling (GD-mode), the complete set of geminal and vicinal homonuclear $\left(J_{\mathrm{H}, \mathrm{H}}\right.$ and $\left.J_{\mathrm{C}, \mathrm{C}}\right)$ as well as heteronuclear $\left(J_{\mathrm{C}, \mathrm{H}}\right)$ coupling constants was obtained for the 4-deoxy- $\beta$-L-threo-hex-4-enopyranosiduronic acid moiety by combination of data from the selectively ${ }^{13} \mathrm{C}$-labeled compounds.

GC-MS analysis was carried out on an Agilent $6890 \mathrm{~N} / 5975 \mathrm{~B}$ instrument in the $\mathrm{EI}(70 \mathrm{eV})$ ionization mode. Melting points, determined on a Kofler-type micro hot stage with Reichert-Biovar microscope, are uncorrected. Elemental analyses were performed by the Microanalytical Laboratory at the University of Vienna. All compounds showed satisfactory microanalytical data within the limits of $0.3 \%$.

Synthesis of the ${ }^{13} \mathrm{C}$-labeled HexA model compounds

The following protocols are presented by means of the non-labeled compounds, with methyl 4-deoxy- $\beta$-Lthreo-hex-4-enopyranosiduronic acid (1, see Scheme 2) being the target. The same synthesis sequence was repeated six times for the six selectively ${ }^{13} \mathrm{C}$-labeled compounds: methyl $1-{ }^{13} \mathrm{C}-4$-deoxy- $\beta$-L-threo-hex-4enopyranosiduronic acid (1a), methyl $2-{ }^{13} \mathrm{C}-4$-deoxy$\beta$-L-threo-hex-4-enopyranosiduronic acid (1b), methyl $3-{ }^{13} \mathrm{C}$-4-deoxy- $\beta$-L-threo-hex-4-enopyranosiduronic acid (1c), methyl $4-{ }^{13} \mathrm{C}-4-$ deoxy- $\beta$-L-threo-hex-4- 


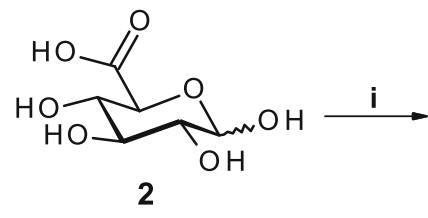

2

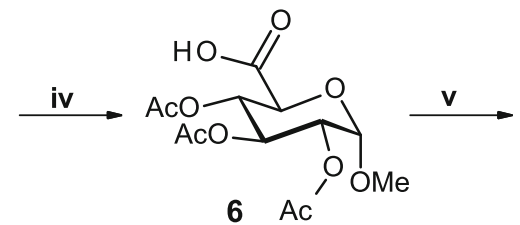

$6 \mathrm{Ac}$

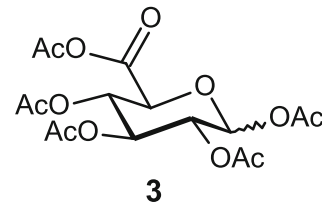

3

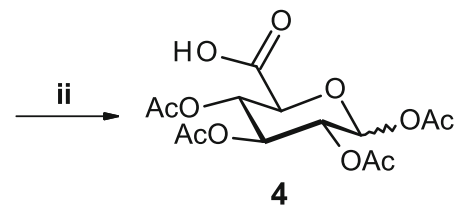

4
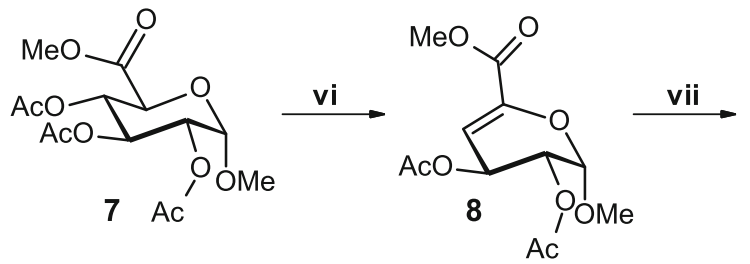

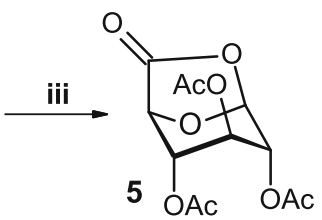

i) $\mathrm{Ac}_{2} \mathrm{O} / \mathrm{I}_{2}$, ii) $\mathrm{THF} / \mathrm{H}_{2} \mathrm{O}$ (v/v=9/1), 88 - $92 \%$ from 2, iii) $\mathrm{SnCl}_{4}, \mathrm{CH}_{2} \mathrm{Cl}_{2}$,

iv) $\mathrm{SnCl}_{4} / \mathrm{TMS}-\mathrm{OMe} / \mathrm{CH}_{2} \mathrm{Cl}_{2}$, then $\mathrm{NaHCO}_{3}$, then $\mathrm{AcOH}, 72-79 \%$ from 4 ,

v) $\mathrm{TMS}_{-} \mathrm{CHN}_{2} / \mathrm{MeOH}, \mathrm{CH}_{2} \mathrm{Cl}_{2}$, vi) $\mathrm{Ac}_{2} \mathrm{O} / \mathrm{Py} / \mathrm{DBU}, 79-83 \%$ from 6 ,

vii) $\mathrm{LiOH} / \mathrm{H}_{2} \mathrm{O} / \mathrm{THF}, 92-94 \%$

Scheme 2 Reaction sequence towards HexA model compound methyl 4-deoxy- $\beta$-L-threo-hex-4-enopyranosiduronic acid (1) starting from D-glucuronic acid

enopyranosiduronic acid (1d), methyl $5-{ }^{13} \mathrm{C}-4-$ deoxy- $\beta$-L-threo-hex-4-enopyranosiduronic acid (1e), and methyl $6-{ }^{13} \mathrm{C}-4$-deoxy- $\beta$-L-threo-hex-4enopyranosiduronic acid (1f), starting from the corresponding ${ }^{13} \mathrm{C}$-labeled D-glucuronic acids. The synthesis followed an optimized synthesis path towards non-labeled model compound $\mathbf{1}$, based on a path previously developed in our group (Tot et al. 2008). This way, the syntheses were performed seven times, i.e. for the seven different isotopomers, and the yield of each step is given as the range between the experiment with the lowest and the highest yield. Yield differences between the runs with different isotopomers were generally below $7 \%$, in most cases below $4 \%$.

D-Glucuronic acid $(2, \mathrm{M}=194.1 \mathrm{~g} / \mathrm{mol}, 5.0 \mathrm{~g}$, $25.76 \mathrm{mmol}$ ) was suspended in acetic anhydride $(75 \mathrm{ml})$ and stirred at $0{ }^{\circ} \mathrm{C}$ for $15 \mathrm{~min}$. Iodine (350 mg, $1.65 \mathrm{mmol}$ ) was added and stirring was continued for $2 \mathrm{~h}$, keeping the temperature strictly below $5{ }^{\circ} \mathrm{C}$ by efficient ice/water bath cooling. The mixture was allowed to reach r.t., and excess acetic anhydride was removed in vacuo at r.t. The residue was diluted with dichloromethane $(120 \mathrm{ml})$, washed three times with cold aqueous $\mathrm{Na}_{2} \mathrm{~S}_{2} \mathrm{O}_{3}(1 \mathrm{M}, 80 \mathrm{ml}$ each), dried over $\mathrm{MgSO}_{4}$, and filtered. After removal of the solvent under reduced pressure, the crude peracetylated mixed anhydride $\mathbf{3}$ was used directly in the next step without further purification. TLC: dichloromethane/ methanol $=9: 1, \mathrm{R}_{f}=0.24 .{ }^{1} \mathrm{H} \mathrm{NMR}\left(\mathrm{CDCl}_{3}\right): \delta 5.82$ $\left(\mathrm{d}, 1 \mathrm{H}, J_{1,2}=6.9, \mathrm{H}-1\right), 5.39(\mathrm{t}, 1 \mathrm{H}, J=9.0, \mathrm{H}-4), 5.30$ (t, 1H, $J=8.3, \mathrm{H}-3), 5.13$ (dd, 1H, H-2), 4.33 (d, 1H, $\mathrm{H}-5$ ), 2.29 (s, 3H, Me in anhydride), 2.15, 2.06, 2.05, $2.04(4 \mathrm{~s}, 4 \times 3 \mathrm{H}$, acetoxy).

Compound $3(\mathrm{M}=404.3 \mathrm{~g} / \mathrm{mol})$ was dissolved in a mixture of THF and water $(50 \mathrm{ml}, \mathrm{v} / \mathrm{v}=9: 1)$ and stirred overnight. $\mathrm{MgSO}_{4}$ was added to bind the water present, and additional $50 \mathrm{~mL}$ of THF was added and the slurry was filtered. The solvent was removed under reduced pressure to give peracetylated acid $4(1,2,3,4$ tetra- $O$-acetyl- $\beta$-D-glucopyranosiduronic acid) which was again used without further purification $(91 \%$, 88-92\% for $\mathbf{4 a - 4 f )}$ ). TLC: dichloromethane/methanol $=3: 1, \mathrm{R}_{f}=0.55 .{ }^{1} \mathrm{H}$ NMR $\left(\mathrm{CDCl}_{3}\right): \delta 5.80(\mathrm{~d}$, $\left.1 \mathrm{H}, J_{1,2}=7.5, \mathrm{H}-1\right), 5.31(\mathrm{~m}, 2 \mathrm{H}, \mathrm{H}-3$ and $\mathrm{H}-4), 5.15$ $\left(\mathrm{m}, 1 \mathrm{H}, J_{2,3}=9.0, \mathrm{H}-2\right), 4.26\left(\mathrm{~m}, 1 \mathrm{H}, J_{4,5}=9.31\right.$, H-5), 2.13, 2.06, 2.05, 2.04 (4 s, $4 \times 3 \mathrm{H}$, acetoxy).

Acid $4(\mathrm{M}=362.3 \mathrm{~g} / \mathrm{mol}, 8.49 \mathrm{~g}, 23.43 \mathrm{mmol})$ was dissolved in dry dichloromethane $(100 \mathrm{ml})$ under argon. $\mathrm{SnCl}_{4}(2.95 \mathrm{ml}, 1.1$ eq. $)$ was added during $10 \mathrm{~min}$ and the reaction mixture was stirred overnight at r.t. Completion of the lactone formation was checked by TLC control: saturated aqueous $\mathrm{NaHCO}_{3}$ solution $(5 \mathrm{ml})$ was added to a $5 \mathrm{ml}$ aliquot and the mixture was vigorously stirred for $30 \mathrm{~min}$ to guarantee intimate mixing of the two phases. The resulting 
viscous white emulsion was filtered under vacuum through a $5 \mathrm{~mm}$ layer of Celite ${ }^{\circledR}$. A filtrate of two phases resulted, of which the aqueous layer was discarded and the organic layer washed with saturated $\mathrm{NaHCO}_{3}$ solution, dried over $\mathrm{MgSO}_{4}$, and filtered. The solvent was removed in vacuo and the remainder, the crude lactone 5, taken for analysis. TLC: hexane/ ethyl acetate $=1: 3, \mathrm{R}_{f}=0.80$, m.p. $72-74{ }^{\circ} \mathrm{C} .{ }^{1} \mathrm{H}$ NMR $\left(\mathrm{CDCl}_{3}\right): \delta 5.92(\mathrm{~s}, 1 \mathrm{H}, \mathrm{H}-1), 4.96(\mathrm{~s}, 1 \mathrm{H}, \mathrm{H}-3)$, 4.82 (s, 1H, H-4), 4.78 (s, 1H, H-2), 4.60 (t, 1H, H-5), 2.19 (s, 6H, 2-O-acetoxy, 4- $O$-acetoxy), 2.10 (s, 3H, 3-O-acetoxy).

To the main reaction mixture, methoxytrimethylsilane (TMSOMe, 1.05 eq., $25 \mathrm{mmol}, 3.15 \mathrm{ml}$ ) was added, and the reaction mixture was left stirring overnight. Saturated aqueous $\mathrm{NaHCO}_{3}$ solution $(50 \mathrm{ml})$ was added and the mixture vigorously stirred for $30 \mathrm{~min}$ to guarantee intimate mixing of the two phases. The resulting viscous white emulsion was left standing for $30 \mathrm{~min}$ and glacial acetic acid was added under $\mathrm{CO}_{2}$ evolution until no more gas was released and two clear phases resulted. The phases were separated and the aqueous phase was extracted with dichloromethane $(3 \times 20 \mathrm{~mL})$. The combined organic phases were washed with brine $(10 \mathrm{ml})$, dried over $\mathrm{MgSO}_{4}$, and filtered. The reaction mixture was concentrated and the crude product was purified by silica gel chromatography using chloroform/ethanol/ water $=5: 2: 0.1$ as eluent, affording 2,3,4-tri- $O$ acetyl-1- $O$-methyl- $\alpha$-D-glucopyranosiduronic acid (6) in $77 \%$ yield $\left(72-79 \%\right.$ for 6a-6f). TLC: $\mathrm{CHCl}_{3} /$ $\mathrm{EtOH} / \mathrm{H}_{2} \mathrm{O}=5: 2: 0.1, \mathrm{R}_{f}=0.31 .{ }^{1} \mathrm{H}$ NMR $\left(\mathrm{CDCl}_{3}\right)$ : $\delta 8.4(\mathrm{br} \mathrm{s}, 1 \mathrm{H}, \mathrm{COOH}), 5.53\left(\mathrm{dd}, 1 \mathrm{H}, J_{2,3}=10.0\right.$, $\left.J_{3,4}=9.5, \mathrm{H}-3\right), 5.22\left(\mathrm{dd}, 1 \mathrm{H}, J_{4,5}=10.1, \mathrm{H}-4\right), 5.06$ (d, 1H, $\left.J_{1,2}=3.5, \mathrm{H}-1\right), 4.92$ (dd, 1H, H-2), 4.32 (d, $1 \mathrm{H}, \mathrm{H}-5), 3.46\left(\mathrm{~s}, 3 \mathrm{H}, \mathrm{OCH}_{3}\right), 2.08,2.04,2.02(3 \mathrm{~s}$, $3 \times 3 \mathrm{H}$, acetoxy).

Peracetylated acid $6(324.28 \mathrm{~g} / \mathrm{mol}, \quad 5.85 \mathrm{~g}$, $18.04 \mathrm{mmol}$ ) was dissolved in dichloromethane $(150 \mathrm{ml})$. Methanol $(5 \mathrm{ml})$ and trimethylsilyldiazomethane (TMSDAM, $1 \mathrm{M}$ in diethyl ether, $21.65 \mathrm{ml}, 1.2$ eq.) were added. Stirring was continued for $1 \mathrm{~h}$ and the mixture was refluxed for $5 \mathrm{~min}$. A $5 \mathrm{ml}$ aliquot was taken, the solvent removed by evaporation and the remainder, the corresponding methyl ester $\mathbf{7}$, analyzed by NMR. Methyl 2,3,4-tri- $O$-acetyl-1-Omethyl- $\alpha$-D-glucopyranosiduronate (7): TLC: $\mathrm{CHCl}_{3}$ / $\mathrm{EtOH}=5: 2, \mathrm{R}_{f}=0.54 .{ }^{1} \mathrm{H} \mathrm{NMR}\left(\mathrm{CDCl}_{3}\right): \delta 5.51$ $\left(\mathrm{dd}, 1 \mathrm{H}, J_{2,3}=9.9, J_{3,4}=8.5, \mathrm{H}-3\right), 5.08(\mathrm{dd}, 1 \mathrm{H}$,
$\left.J_{4,5}=10.3, \mathrm{H}-4\right), 5.16\left(\mathrm{~d}, 1 \mathrm{H}, J_{1,2}=4.4, \mathrm{H}-1\right), 5.00$ (dd, 1H, H-2), 4.28 (d, 1H, H-5), 3.46 (s, 3H, $\mathrm{OCH}_{3}$ ), 3.24 (s, 3H, COOMe), 2.08, 2.04, 2.02 (3 s, $3 \times 3 \mathrm{H}$, acetoxy).

After concentrating the main reaction mixture to a volume of about $50 \mathrm{~mL}$, a mixture of acetic anhydride and pyridine $(\mathrm{v} / \mathrm{v}=1: 1,100 \mathrm{ml})$ was added, along with DBU (3 $\mathrm{ml})$ as a catalyst. The mixture was stirred for $72 \mathrm{~h}$ at r.t. The solvent was removed in vacuo, the remainder diluted with EtOAc $(50 \mathrm{ml})$, washed with brine $(2 \times 10 \mathrm{ml})$, and dried over $\mathrm{MgSO}_{4}$. The solvent was evaporated and the crude product was purified by column chromatography on silica gel (hexane/ethyl acetate, $\mathrm{v} / \mathrm{v}=1: 5)$ to give $\mathbf{8}$, the acetyl-protected methyl ester of the target product $(83 \%, 79-83 \%$ for 8a-8f). TLC: EtOAc/MeOH $=3: 1, \mathrm{R}_{f}=0.54 .{ }^{1} \mathrm{H}$ NMR $\left(\mathrm{CD}_{3} \mathrm{OD}\right): \delta 6.04\left(\mathrm{~d}, 1 \mathrm{H}, J_{3,4}=3.6, \mathrm{H}-4\right), 5.57$ $\left(\mathrm{dd}, 1 \mathrm{H}, J_{2,3}=8.6, \mathrm{H}-3\right), 5.22\left(\mathrm{~d}, 1 \mathrm{H}, J_{1,2}=3.0, \mathrm{H}-1\right)$, 5.08 (dd, $1 \mathrm{H}, \mathrm{H}-2), 3.52\left(\mathrm{~s}, 3 \mathrm{H}, \mathrm{OCH}_{3}\right), 3.28(\mathrm{~s}, 3 \mathrm{H}$, COOMe $), 2.07,2.06(2 \mathrm{~s}, 2 \times 3 \mathrm{H}$, acetoxy $)$.

Methyl ester 8 (288.25 g/mol, $4.32 \mathrm{~g}, 14.97 \mathrm{mmol})$ was suspended in $50 \mathrm{ml}$ of aqueous $\mathrm{LiOH}$ solution (0.1 $\mathrm{M}$ in $\left.\mathrm{H}_{2} \mathrm{O} / \mathrm{THF}, \mathrm{v} / \mathrm{v}=2: 1\right)$ at $0{ }^{\circ} \mathrm{C}$ (ice bath) and was stirred for $30 \mathrm{~min}$. The reaction mixture was diluted with $50 \mathrm{~mL}$ of water and acidified to $\mathrm{pH} 2$ with ion exchange resin Dowex $50\left(\mathrm{H}^{+}\right.$form). The ion exchanger was removed by filtration, the mixture was concentrated in vacuo at r.t. and the precipitate lyophilized to dryness, affording 1 (190.15 g/mol) as colorless amorphous solid which was purified by recrystallization from methanol $(2.62 \mathrm{~g}, 13.77 \mathrm{mmol}$, yield $92 \%, 92-94 \%$ for 1a-1f). TLC: $\mathrm{MeOH} / \mathrm{CH}_{2} \mathrm{Cl}_{2} /$ $\mathrm{H}_{2} \mathrm{O}=5: 10: 1, \mathrm{R}_{f}=0.6$.

The complete set of NMR data of methyl 4-deoxy- $\beta$ L-threo-hex-4-enopyranosiduronic acid (1) and its corresponding ${ }^{13} \mathrm{C}$-labeled isotopomers (1a-1f), including the homonuclear $(\mathrm{H}, \mathrm{H}$ and $\mathrm{C}, \mathrm{C})$ and heteronuclear $(\mathrm{C}, \mathrm{H})$ coupling constants, are summarized in Table 1 $\left({ }^{1} \mathrm{H}\right.$ domain) and Table $2\left({ }^{13} \mathrm{C}\right.$ domain).

Primary degradation products of the HexA model compounds-synthesis of 5-formyl-2-furancarboxylic acid (9 and isotopomers $9 \mathbf{a}-\mathbf{9 f}$ ) and 2-furancarboxylic acid (10 and isotopomers 10b-10f)

Methyl 4-deoxy- $\beta$-L-threo-hex-4-enopyranosiduronic acid (1, $190 \mathrm{mg}, 1 \mathrm{mmol})$, or its isotopomers 1a-1f, were dissolved in $10 \mathrm{ml}$ of phosphate buffer 


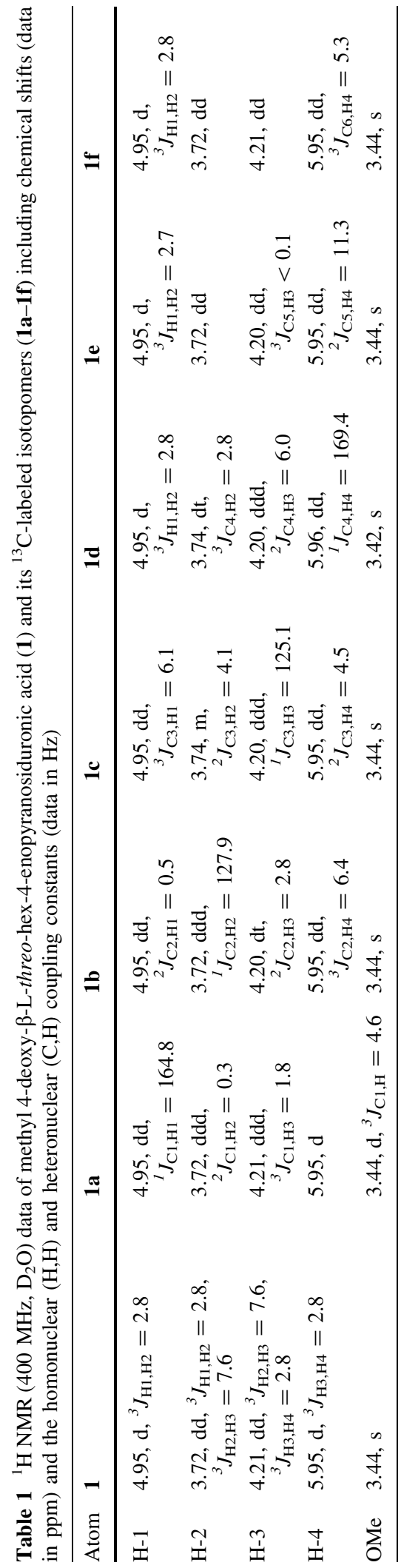

$(\mathrm{pH}=4.5)$. The mixture was stirred under argon and under exclusion of light (vessel wrapped in aluminum foil) for about $19 \mathrm{~h}$ at r.t., until TLC control (MeOH/ $\mathrm{CH}_{2} \mathrm{Cl}_{2} / \mathrm{H}_{2} \mathrm{O}=5: 10: 1, \mathrm{R}_{f}=0.60$ ) showed that the starting material was consumed completely. Longer reaction times will shift the ratio between the products $\mathbf{9}$ and $\mathbf{1 0}$ in favor of the latter (18\% of $\mathbf{9}$ and $75 \%$ of $\mathbf{1 0}$ after $72 \mathrm{~h}$ ). Powdered $\mathrm{Na}_{2} \mathrm{SO}_{4}$ was added until the mixture was saturated and no more salt dissolved. The mixture was extracted with dichloromethane $(3 \times 20 \mathrm{ml})$, the extracts were combined, and the solvent removed in vacuo at r.t. The remaining waxy and slightly yellow remainder was chromatographed on silica gel using chloroform/ethanol/water $=5: 2: 0.1$ as eluent, providing 5-formyl-2-furancarboxylic acid (9) as the first main fraction (140.1 g/mol, $102.25 \mathrm{mg}, 73 \%$, 56-82\% for 9a-9f) and 2-furancarboxylic acid (10) as the second main fraction $(112.1 \mathrm{~g} / \mathrm{mol}, 25.8 \mathrm{mg}, 23 \%, 12-41 \%$ for 10b-10f).

The complete sets of NMR data of 5-formyl-2furancarboxylic acid (9) and 2-furancarboxylic acid (10) and their corresponding ${ }^{13} \mathrm{C}$-labeled isotopomers (9a-9f and 10b-10f), including the homonuclear $(\mathrm{H}, \mathrm{H}$ and $\mathrm{C}, \mathrm{C})$ and heteronuclear $(\mathrm{C}, \mathrm{H})$ coupling constants, are summarized in Tables 3 and $6\left({ }^{1} \mathrm{H}\right.$ domain) as well as Tables 4, 5, 7 and $8\left({ }^{13} \mathrm{C}\right.$ domain $)$, respectively.

5-Formyl-2-furancarboxylic acid and its isotopomers $(\mathbf{9}, \mathbf{9 a}-9 \mathbf{f})$

Note that the numbering for compound $\mathbf{9}$ and its isotopomers (see formula inset) does not correspond to the IUPAC numbering, but was derived from parent compound 1 for a better illustration of the mechanistic and structural dependence.

2-Furancarboxylic acid and its isotopomers (10, 10b-10f)

Note that the numbering for compound $\mathbf{1 0}$ and its isotopomers (see formula inset) does not correspond to the IUPAC numbering, but was derived from parent compound 1 to better illustrate the mechanistic and structural dependence.

Formic acid- ${ }^{13} \mathrm{C}$ (11a) was obtained upon degradation of HexA model compound 1a via intermediate 9a besides non-labeled 2-furancarboxylic acid $\mathbf{1 0}$ (therefore no compound "10a" is listed as the ${ }^{13} \mathrm{C}$ - 
Table $2{ }^{13} \mathrm{C}$ NMR $\left(100 \mathrm{MHz}, \mathrm{D}_{2} \mathrm{O}\right)$ data of methyl 4-deoxy- $\beta$-L-threo-hex-4-enopyranosiduronic acid (1) and its ${ }^{13} \mathrm{C}-1 \mathrm{abeled}$ isotopomers (1a-1f) including chemical shifts (data in ppm) and the homonuclear (C,C) couplings (data in $\mathrm{Hz}$ )

\begin{tabular}{|c|c|c|c|c|c|c|c|}
\hline Atom & 1 & $1 \mathbf{a}$ & $1 b$ & $1 c$ & 1d & $1 e$ & 1f \\
\hline C-1 & 100.5 & $100.5^{*}$ & $\begin{array}{l}100.6, \mathrm{~d}, \\
{ }^{1} J_{\mathrm{C}, \mathrm{C}}=38.5\end{array}$ & $\begin{array}{l}100.5, \mathrm{~d}, \\
{ }^{2} J_{\mathrm{C}, \mathrm{C}}=2.4\end{array}$ & $\begin{array}{l}100.5, \mathrm{~d}, \\
{ }^{3} J_{\mathrm{C}, \mathrm{C}}=0.3\end{array}$ & $\begin{array}{l}100.5, \mathrm{~d}, \\
{ }^{2} J_{\mathrm{C}, \mathrm{C}}=2.5\end{array}$ & $\begin{array}{l}100.5, \mathrm{~d}, \\
{ }^{3} J_{\mathrm{C}, \mathrm{C}}=3.6\end{array}$ \\
\hline $\mathrm{C}-2$ & 69.6 & $\begin{array}{l}69.8, \mathrm{~d}, \\
{ }^{1} J_{\mathrm{C}, \mathrm{C}}=38.5\end{array}$ & $69.7 *$ & $\begin{array}{l}69.7, \mathrm{~d}, \\
{ }^{1} J_{\mathrm{C}, \mathrm{C}}=42.6\end{array}$ & $\begin{array}{l}69.6, \mathrm{~d}, \\
{ }^{2} J_{\mathrm{C}, \mathrm{C}}=2.6\end{array}$ & $\begin{array}{l}69.6, \mathrm{~d} \\
{ }^{3} J_{\mathrm{C}, \mathrm{C}}<0.1\end{array}$ & 69.6 \\
\hline $\mathrm{C}-3$ & 65.6 & $\begin{array}{l}65.6, \mathrm{~d}, \\
{ }^{2} J_{\mathrm{C}, \mathrm{C}}=2.4\end{array}$ & $\begin{array}{l}65.7, \mathrm{~d}, \\
{ }^{1} J_{\mathrm{C}, \mathrm{C}}=42.6\end{array}$ & $65.6^{*}$ & $\begin{array}{l}65.6, \mathrm{~d}, \\
{ }^{1} J_{\mathrm{C}, \mathrm{C}}=40.6\end{array}$ & $\begin{array}{l}65.6, \mathrm{~d}, \\
{ }^{2} J_{\mathrm{C}, \mathrm{C}}=3.1\end{array}$ & $\begin{array}{l}65.6, \mathrm{~d} \\
{ }^{3} J_{\mathrm{C}, \mathrm{C}}\end{array}=3.5$ \\
\hline C-4 & 111.6 & $\begin{array}{l}111.6, \mathrm{~d}, \\
{ }^{3} J_{\mathrm{C}, \mathrm{C}}=0.3\end{array}$ & $\begin{array}{l}111.6, \mathrm{~d}, \\
{ }^{2} J_{\mathrm{C}, \mathrm{C}}=2.6\end{array}$ & $\begin{array}{l}111.6, \mathrm{~d}, \\
{ }^{1} J_{\mathrm{C}, \mathrm{C}}=40.6\end{array}$ & $111.7^{*}$ & $\begin{array}{l}111.8, \mathrm{~d}, \\
{ }^{1} J_{\mathrm{C}, \mathrm{C}}=54.2\end{array}$ & $\begin{array}{l}111.5, \mathrm{~d}, \\
{ }^{2} J_{\mathrm{C}, \mathrm{C}}=0.4\end{array}$ \\
\hline C-5 & 141.1 & $\begin{array}{l}141.0, \mathrm{~d}, \\
{ }^{2} J_{\mathrm{C}, \mathrm{C}}=2.5\end{array}$ & $\begin{array}{l}141.1, \mathrm{~d}, \\
{ }^{3} J_{\mathrm{C}, \mathrm{C}}<0.1\end{array}$ & $\begin{array}{l}141.1, \mathrm{~d}, \\
{ }^{2} J_{\mathrm{C}, \mathrm{C}}=3.1\end{array}$ & $\begin{array}{l}141.4, \mathrm{~d}, \\
{ }^{1} J_{\mathrm{C}, \mathrm{C}}=54.2\end{array}$ & $141.1^{*}$ & $\begin{array}{l}141.2, \mathrm{~d}, \\
{ }^{1} J_{\mathrm{C}, \mathrm{C}}=74.0\end{array}$ \\
\hline $\mathrm{COOH}$ & 166.3 & $\begin{array}{l}166.3, \mathrm{~d}, \\
{ }^{3} J_{\mathrm{C}, \mathrm{C}}=3.5\end{array}$ & 166.2 & $\begin{array}{l}166.6, \mathrm{~d}, \\
{ }^{3} J_{\mathrm{C}, \mathrm{C}}=3.6\end{array}$ & $\begin{array}{l}166.6, \mathrm{~d} \\
{ }^{2} J_{\mathrm{C}, \mathrm{C}}=0.4\end{array}$ & $\begin{array}{l}166.1, \mathrm{~d}, \\
{ }^{1} J_{\mathrm{C}, \mathrm{C}}=74.0\end{array}$ & $166.5^{*}$ \\
\hline $\mathrm{OMe}$ & 56.8 & $\begin{array}{l}56.8, \mathrm{~d}, \\
{ }^{2} J_{\mathrm{C}, \mathrm{C}}=2.5\end{array}$ & $\begin{array}{l}56.8, \mathrm{~d}, \\
{ }^{3} J_{\mathrm{C}, \mathrm{C}}=0.3\end{array}$ & 56.8 & 56.8 & 56.8 & 56.8 \\
\hline
\end{tabular}

The heteronuclear coupling constants $(\mathrm{C}, \mathrm{H})$ are listed in Table 1

$*>99.9 \%{ }^{13} \mathrm{C}$

label at $\mathrm{C} 1$ is cleaved off as formic acid in this reaction).

${ }^{1} \mathrm{H}$ NMR (DMSO-d ${ }_{6}$ ): $\delta 8.01,{ }^{1} J_{\mathrm{C}, \mathrm{H}}=215.3 .{ }^{13} \mathrm{C}$ NMR (DMSO-d $\left.{ }_{6}\right): \delta 163.76 .{ }^{1} \mathrm{H}$ NMR $\left(\mathrm{D}_{2} \mathrm{O}\right): \delta 8.24$, ${ }^{1} J_{\mathrm{C}, \mathrm{H}}=219.2 .{ }^{13} \mathrm{C}$ NMR $\left(\mathrm{D}_{2} \mathrm{O}\right): \delta 168.3$.

\section{Results and discussion}

Synthesis of the HexA model compound

HexA model compound 1 represents the 4-deoxy- $\beta$-Lthreo-hex-4-enopyranosiduronic acid side-chain moiety in xylans, with the backbone chain being mimicked by the methyl aglycon. Under the harsh conditions of pulping, these residues are formed by methanol elimination from the 4-O-methylglucuronic acids that are $1 \rightarrow 2-\alpha$-glycosidically linked to the xylopyranan. The synthesis of the model compound was thoroughly optimized with regard to yield and recycling of side products in order to minimize the loss of rather costly ${ }^{13} \mathrm{C}$-labeled material in the subsequent synthesis of the six isotopomers 1a-1f. The synthesis scheme, in principle, followed a sequence that had been previously developed in our group (Tot et al. 2008), with some improvements to work more efficiently in the case of the labeled compounds. In particular, we tried to employ one-pot procedures whenever possible and reduce the number of (chromatographic) purifications between the steps to minimize inevitable compound losses.

The synthesis towards methyl 4-deoxy- $\beta$-L-threohex-4-enopyranosiduronic acid (1) comprised a seven step sequence starting from readily accessible D-glucopyranosiduronic acid (see Scheme 2). This starting material is also commercially available, albeit quite costly, with a mono- ${ }^{13} \mathrm{C}$-label at each of the six carbon atoms. In the first step, the glucopyranosiduronic acid 2 was peracetylated with acetic anhydride/iodine. Under these conditions, also the carboxylic acid function was acetylated so that a mixed anhydride $\mathbf{3}$ was formed, which was readily cleaved by water into the free acid 4. Although alternative acetylation conditions, such as standard amine catalysis, avoid the additional step of anhydride formation and cleavage, they are still far inferior by giving lactone and furanoid by-products that are completely absent upon iodine catalysis.

The following two transformations were the key steps in the sequence, both carried out as one-pot reaction and promoted by the same reagent, namely $\mathrm{SnCl}_{4}$. Treatment of acid 4 with $\mathrm{SnCl}_{4}$ afforded the bicyclic, $\beta$-configured 1,6-lactone $\mathbf{5}$ under pyranoside ring inversion. Addition of methanol and methoxytrimethylsilane opened this lactone again in a fully regioselective manner: the nucleophilic attack 


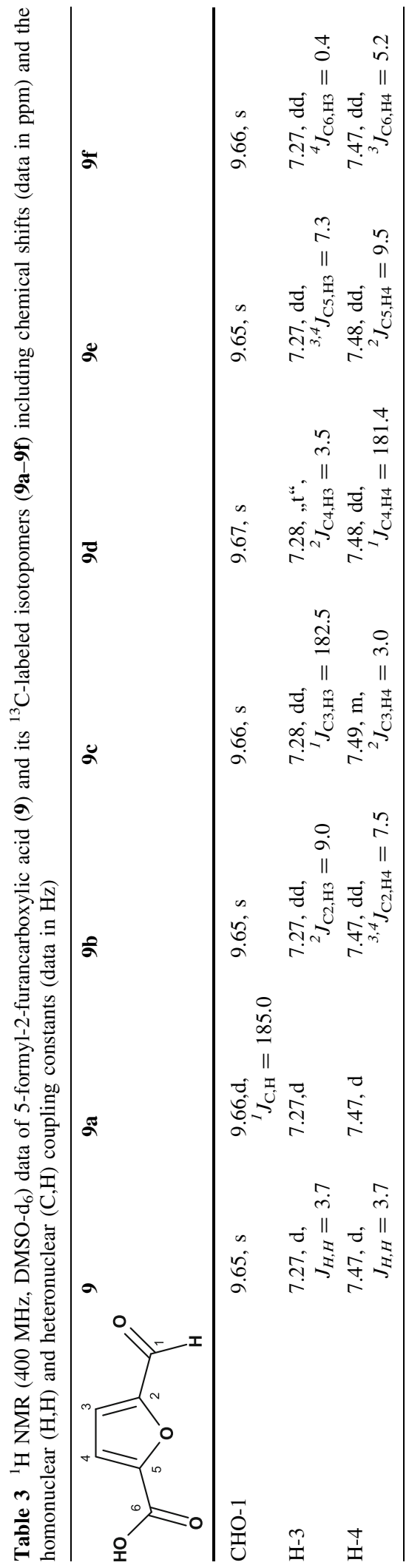

at $\mathrm{C}-1$ with its axial oxycarbonyl substituent gave exclusively the $\alpha$-configured methyl glycoside $\mathbf{6}$ by a second ring conversion, so that the desired product stereochemistry at C-1 was already set in this step. The synthetic "detour" via lactone $\mathbf{5}$ cannot be avoided since direct glycosidation of uronic acid donors gives inferior yields in most cases due to their low reactivity. Acid $\mathbf{6}$ was the first intermediate in the sequence that required chromatographic purification.

Selective elimination of the C-4-substituent in compound $\mathbf{6}$ was synthetically challenging. Although it is favored over the elimination of other substituents because the formed double bond is in conjugation with the carboxyl group ( $\beta$-elimination), this effect is not very pronounced and-in general-elimination has to proceed from the disfavored synclinal conformation. It was known from previous work that a similar reaction starting from galacto-configured precursors went much more smoothly due to their favorable antiperiplanar arrangement (Tot et al. 2008). However, D-galactose (or even D-galactopyranosiduronic acid) is not available in suitably ${ }^{13} \mathrm{C}$-labeled forms, so the synthesis had to cope with the respective commercially available gluco-compounds. Generally, elimination from the free acid $\mathbf{6}$ did not work better than giving a $40 \%$ yield after optimization, a rather meager outcome in view of the restraints by the costly isotopically labeled compounds. Analysis of the byproducts showed the carboxylic moiety to be centrally involved, so that protection of that function appeared to be a good idea. Indeed, protection of the $\mathrm{COOH}$ group as its methyl ester 7 immediately doubled the yield to about $80 \%$, which was an acceptable outcome, especially since ester formation before the elimination and deprotection after elimination (removal of acetates from the hydroxyl groups and methyl deprotection of the carboxylic acid function) were virtually quantitative and did not further diminish the yields. The methylation of $\mathbf{6}$ was carried out with trimethylsilyl-diazomethane (Hoai et al. 2004; Tot et al. 2009). Simultaneous deprotection of $\mathrm{COOH}$ and $\mathrm{OH}$ functions in $\mathbf{8}$ was accomplished with $\mathrm{LiOH}$ in water/THF, (Adorjan et al. 2006) which was superior to both other alkali hydroxides and Zemplén deprotection. The elimination step itself was catalyzed by DBU in acetic anhydride/pyridine (Otonani and Yosizawa 1987). 


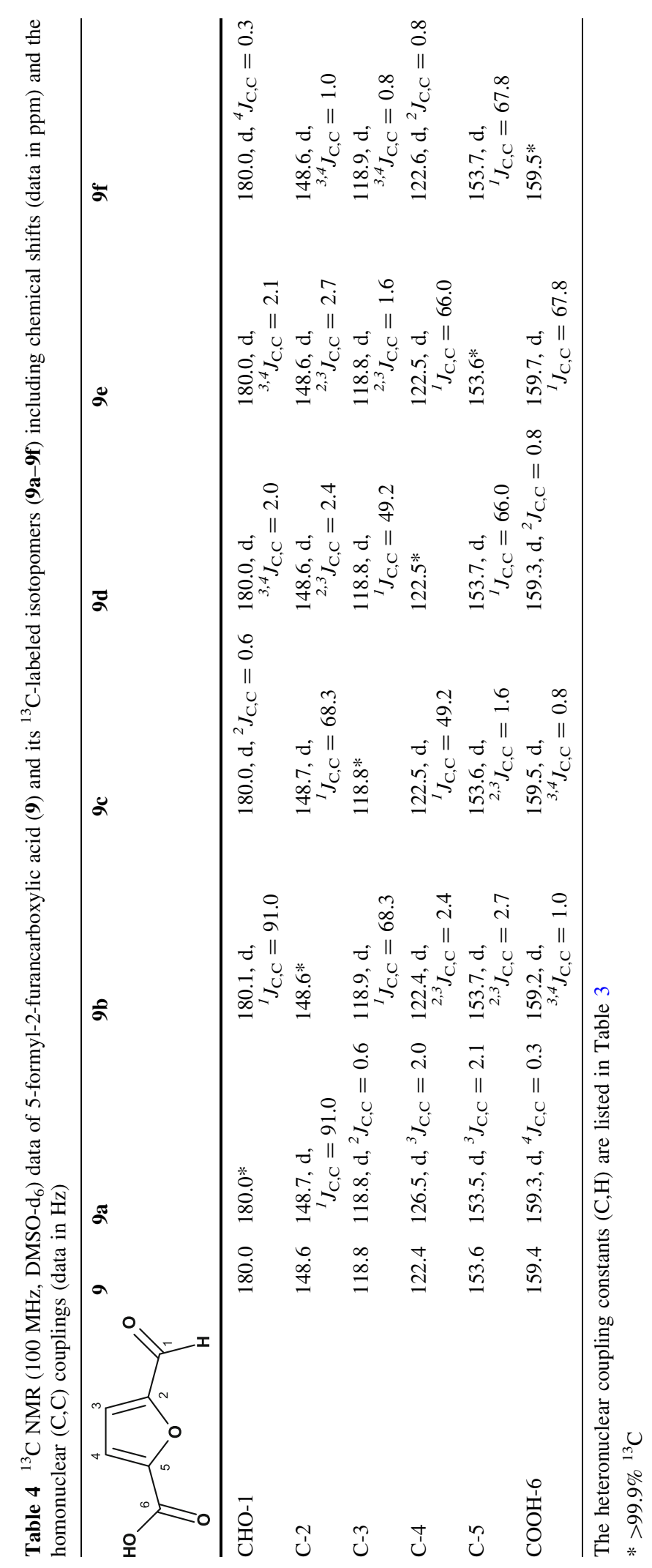


Table $5{ }^{13} \mathrm{C}$ NMR resonances of 5-formyl-2-furancarboxylic acid (9) recorded in $\mathrm{D}_{2} \mathrm{O}$ and DMSO-d $\mathrm{d}_{6}$ and the heteronuclear couplings $\left(J_{\mathrm{C}, \mathrm{H}}\right.$, data in $\left.\mathrm{Hz}\right)$, cf. Table 3

\begin{tabular}{|c|c|c|c|}
\hline $\int_{0}^{\text {Ho }}$ & $\mathrm{D}_{2} \mathrm{O}$ & DMSO- $_{6}$ & Multiplicity and $J_{\mathrm{C}-\mathrm{H}}\left(\mathrm{DMSO}-\mathrm{d}_{6}\right)$ \\
\hline $\mathrm{C}-2$ & 151.9 & 148.64 & $\mathrm{dd},{ }^{2} J=9.0,{ }^{3,4} J=7.5$ \\
\hline $\mathrm{C}-3$ & 121.6 & 118.80 & $\mathrm{dd},{ }^{I} J=182.5,{ }^{2} J=3.0$ \\
\hline $\mathrm{C}-4$ & 126.5 & 122.43 & $\mathrm{dd},{ }^{l} J=181.4,{ }^{2} J=3.5$ \\
\hline $\mathrm{C}-5$ & 155.8 & 153.64 & $\mathrm{ddd},{ }^{3} J=32.3(\mathrm{OH}),{ }^{2} J=9.5,{ }^{3,4} J=7.3$ \\
\hline $\mathrm{COOH}-6$ & 164.6 & 159.40 & $\mathrm{~s}$ \\
\hline CHO-1 & 184.5 & 180.05 & $\mathrm{~d},{ }^{1} J=185.0$ \\
\hline
\end{tabular}

The long reaction times used $(72 \mathrm{~h})$ are necessary for complete conversion, since reaction temperatures above $30{ }^{\circ} \mathrm{C}$ must be avoided as they caused the yield to decrease drastically, going down to $58 \%$ and to $24 \%$ at 50 and $65{ }^{\circ} \mathrm{C}$, respectively. The sequence from lactone $\mathbf{6}$ to target $\mathbf{1}$ was done as one-pot conversion with recrystallization as the final purification step. The whole sequence thus required only one intermediate column chromatography and one recrystallization step. The overall yield ranged between 42 and $46 \%$ over 7 steps, which was well acceptable also for the labeled compounds.

\section{${ }^{13} \mathrm{C}$ isotopomers of the HexA model compound and NMR connectivities}

The synthesis sequence of Scheme 2 was repeated six times, starting with D-glucuronic acids each carrying a ${ }^{13} \mathrm{C}$-monolabel at one of the six carbon atoms. This way, the isotopically labeled HexA model compounds methyl $1-{ }^{13} \mathrm{C}-4$-deoxy- $\beta$-L-threo-hex-4-enopyranosiduronic acid (1a), methyl $2-{ }^{13} \mathrm{C}-4-\operatorname{deoxy}-\beta-\mathrm{L}-$ threo-hex-4-enopyranosiduronic acid (1b), methyl $3-{ }^{13} \mathrm{C}$-4-deoxy- $\beta$-L-threo-hex-4-enopyranosiduronic acid (1c), methyl $4-{ }^{13} \mathrm{C}-4$-deoxy- $\beta$-L-threo-hex-4enopyranosiduronic acid (1d), methyl $5-{ }^{13} \mathrm{C}-4-$ deoxy- $\beta$-L-threo-hex-4-enopyranosiduronic acid (1e), and methyl $6-{ }^{13} \mathrm{C}-4$-deoxy- $\beta$-L-threo-hex-4-enopyranosiduronic acid (1f) were provided. Their structures are given in Scheme 3, indicating the ${ }^{13} \mathrm{C}$-label by a red dot.
Before starting mechanistic studies on HexA degradation and chromophore formation, there was a more immediate benefit from the availability of the six isotopomers: a full description of the NMR spin system of methyl 4-deoxy- $\beta$-L-threo-hex-4-enopyranosiduronic acid. Besides the NMR chemical shifts in the ${ }^{1} \mathrm{H}$ and ${ }^{13} \mathrm{C}$ domain as obvious and readily available data, a complete set of connectivities became accessible, describing all coupling constants of the system, i.e. direct, vicinal, geminal and long-range coupling constants for both homonuclear $(\mathrm{H}-\mathrm{H}$ and $\mathrm{C}-$ C) and heteronuclear (C-H) couplings. Such full connectivity data are rather rare for reasonably large spin systems (with more than 3-4 carbons) as they usually require isotopically labeled or perlabeled compounds (Kalinowski et al. 1984).

The ${ }^{3} J$ homonuclear $\mathrm{H}, \mathrm{H}$ coupling was visible for all vicinal proton pairs, with values of $2.8 \mathrm{~Hz}$ for ${ }^{3} J_{\mathrm{H} 1, \mathrm{H} 2}$ and ${ }^{3} J_{\mathrm{H} 3, \mathrm{H} 4}$ and $7.6 \mathrm{~Hz}$ for ${ }^{3} J_{\mathrm{H} 2, \mathrm{H} 3}$. The homonuclear, direct $\mathrm{C}, \mathrm{C}$ couplings ranged between about $40 \mathrm{~Hz}$ for ${ }^{1} J_{\mathrm{C} 1, \mathrm{C} 2},{ }^{1} J_{\mathrm{C} 2, \mathrm{C} 3}$ and ${ }^{1} J_{\mathrm{C} 3, \mathrm{C} 4}$ over $54.2 \mathrm{~Hz}$ for ${ }^{1} J_{\mathrm{C} 4, \mathrm{C} 5}$ to ${ }^{1} J_{\mathrm{C} 5, \mathrm{C} 6}=74.0 \mathrm{~Hz}$, and fell thus in the expected regions. ${ }^{2} J_{\mathrm{C}, \mathrm{C}}$ couplings were about 2.5-3.0 Hz between $\mathrm{C} 1-\mathrm{C} 3, \mathrm{C} 2-\mathrm{C} 4, \mathrm{C} 3-\mathrm{C} 5$ and $\mathrm{C} 5-$ $\mathrm{C} 1$ and $0.4 \mathrm{~Hz}$ for the $\mathrm{C} 4-\mathrm{C} 6$ coupling. ${ }^{3} J_{\mathrm{C}, \mathrm{C}}$ couplings were rather small $(<0.5 \mathrm{~Hz})$ for $\mathrm{C} 1-\mathrm{C} 4$, $\mathrm{C} 2-\mathrm{C} 5$, and $\mathrm{C} 2-\left(\mathrm{OCH}_{3}\right)$, but larger for the couplings involving $\mathrm{C} 6(3.5 \mathrm{~Hz}$ to $\mathrm{C} 1$ via the ring oxygen and $3.6 \mathrm{~Hz}$ to $\mathrm{C} 3$ ). These ${ }^{3} J_{\mathrm{C}, \mathrm{C}}$ couplings are dependent on the dihedral angle (Severson and Maciel 1984; Karplus 1963) in a way vicinal protons are, for which this dependence is usually displayed as the well- 

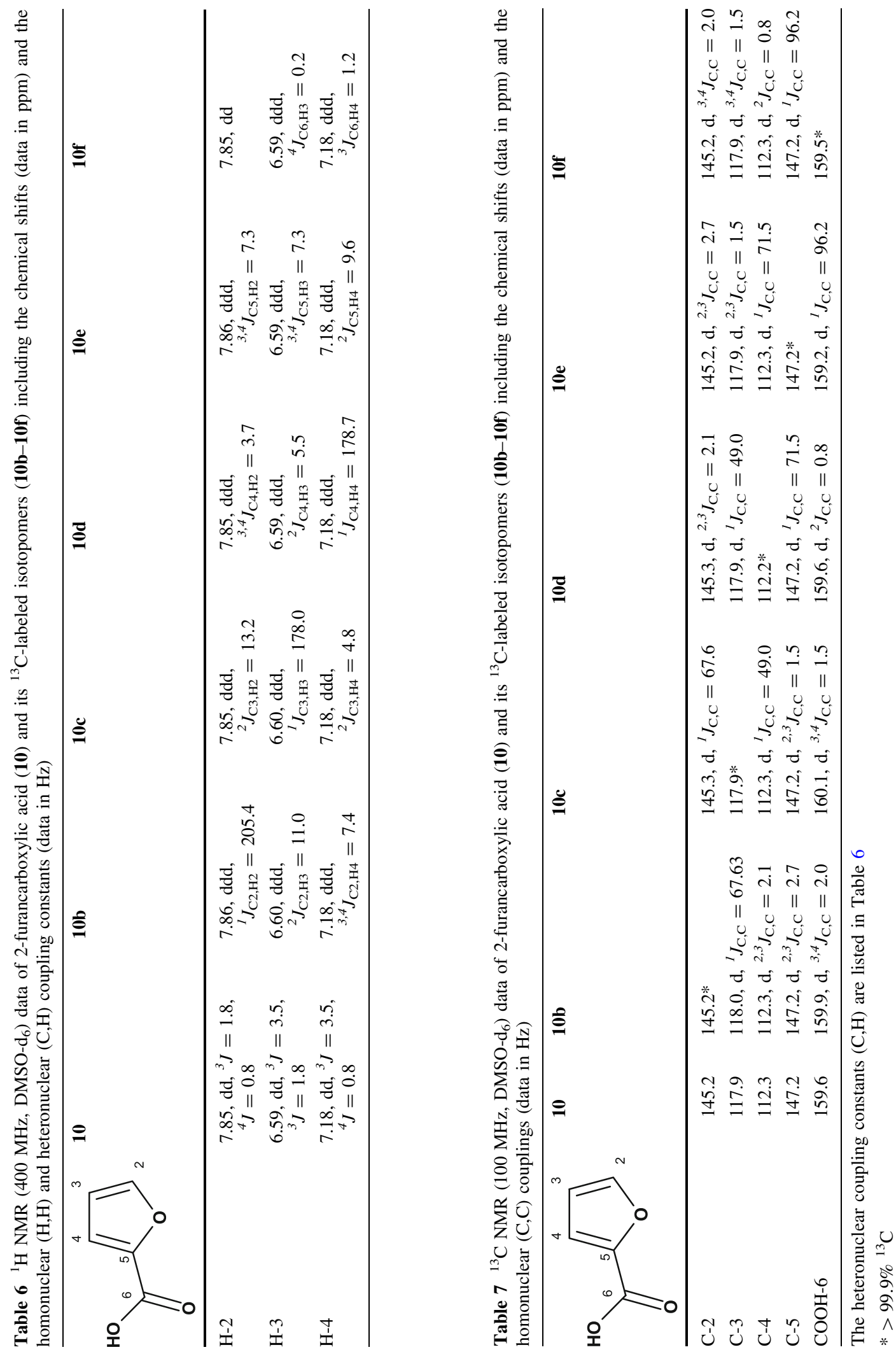
Table $8{ }^{13} \mathrm{C}$ NMR resonances of 2-furancarboxylic acid (10) recorded in $\mathrm{D}_{2} \mathrm{O}$ and DMSO- $\mathrm{d}_{6}$ and heteronuclear couplings $\left(J_{\mathrm{C}, \mathrm{H}}\right.$, data in $\left.\mathrm{Hz}\right)$, cf. Table 6

Scheme 3 Structures of the isotopically labeled HexA model compounds 1a-1f. The position of the ${ }^{13} \mathrm{C}$-label $\left(>99 \%{ }^{13} \mathrm{C}\right)$ is indicated by a red dot

\begin{tabular}{llll}
\hline & & & \\
& & & \\
$\mathrm{C}-2$ & & & \\
$\mathrm{C}-3$ & 150.32 & 147.17 & $\mathrm{ddd},{ }^{1} J=205.4,{ }^{2} J=11.0,{ }^{3,4} J=7.4$ \\
$\mathrm{C}-4$ & 115.07 & 112.28 & $\mathrm{ddd},{ }^{1} J=178.0,{ }^{2} J=13.2,{ }^{2} J=4.8$ \\
$\mathrm{C}-6$ & 122.00 & 117.92 & $\mathrm{ddd},{ }^{1} J=178.8,{ }^{2} J=5.5,{ }^{3,4} J=3.7$ \\
& 146.89 & 145.23 & $\mathrm{ddd},{ }^{2} J=9.6,{ }^{3,4} J=7.3,{ }^{3,4} J=7.3$ \\
& 164.91 & 159.61 & $\mathrm{~s}$
\end{tabular}
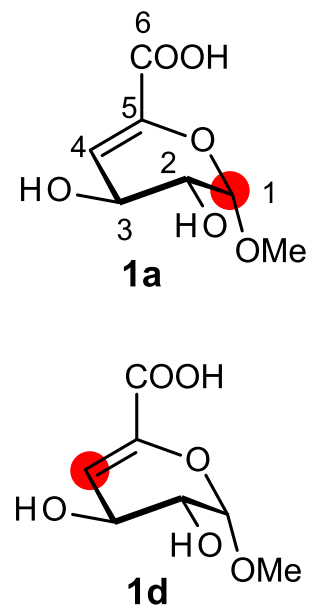<smiles>CO[C@H]1O[C@H](C(=O)O)C=C(C(=O)O)[C@H]1O</smiles><smiles>CO[C@H]1O[C@H](C(=O)O)[C@@H](O)C=C(O)[C@H]1O</smiles><smiles>CO[C@H]1O[C@@H](C(=O)O)[C@H](O)[C@H](O)C=C1C(=O)O</smiles><smiles>CO[C@H]1O[C@H](C(=O)O)[C@@H](O)[C@H](O)[C@H]1O</smiles>

known Karplus curve (Karplus 1963; Marquez et al. 2001).

The direct heteronuclear couplings, i.e. ${ }^{1} J_{\mathrm{C}-\mathrm{H}}$, were, of course, almost two orders of magnitude larger than those over two or three bonds. Longer couplings were not observed. ${ }^{1} J_{\mathrm{C}-\mathrm{H}}$ involving the anomeric carbon and the $\mathrm{sp}^{2}$-hybridized $\mathrm{C} 4$ are 165 and $169 \mathrm{~Hz}$, respectively, while those at the $\mathrm{sp}^{3}$ carbons $\mathrm{C} 2$ and $\mathrm{C} 3$ are around $125 \mathrm{~Hz}$. The vicinal (two bonds) and geminal (three bonds) coupling fell generally between 2 and $6 \mathrm{~Hz}$, with the exceptions of ${ }^{3} J_{\mathrm{C} 5, \mathrm{H} 3}<0.1 \mathrm{~Hz}$ and ${ }^{2} J_{\mathrm{C} 5, \mathrm{H} 4}=11.3 \mathrm{~Hz}$. The coupling constants (connectivities) in the spin system of $\mathbf{1}$ are summarized in Scheme 4 as well as Tables 1 and 2 (see experimental section).

\section{Stability of the HexA model compound}

The labeled model compounds were expected to be quite helpful tools in monitoring the fate of HexA

\section{.}


Scheme 4 Full analysis of the NMR connectivities (homonuclear and heteronuclear couplings) in HexA model compound $\mathbf{1}$. Couplings are displayed with arrows; $J$ values are given in $\mathrm{Hz}$ throughout

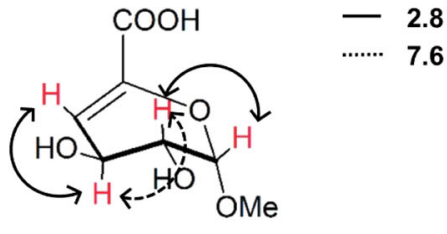

(a) $\mathrm{H}-\mathrm{H}$ homonuclear ${ }^{3} \mathrm{~J}$ coupling (vicinal).

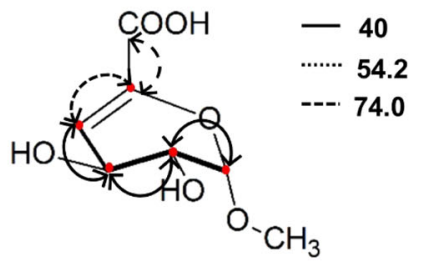

(b) $\mathrm{C}-\mathrm{C}$ homonuclear ${ }^{1} \mathrm{~J}$ coupling (one bond).

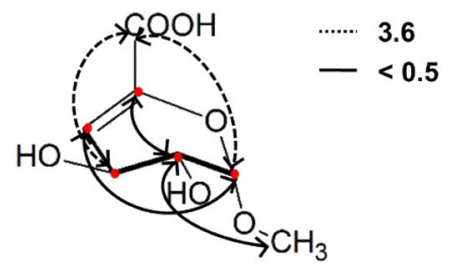

(d) C-C homonuclear ${ }^{3} \mathrm{~J}$ coupling (vicinal).

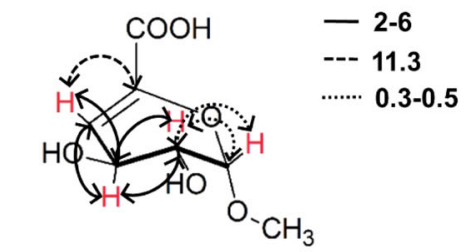

(f) $\mathrm{C}-\mathrm{H}$ heteronuclear ${ }^{2} \mathrm{~J}$ coupling (geminal).

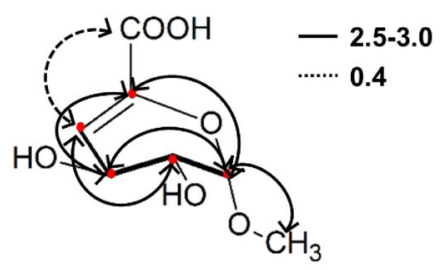

(c) C-C homonuclear ${ }^{2} J$ coupling (geminal).

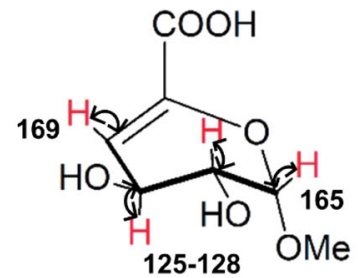

(e) C-H heteronuclear ${ }^{1} \mathrm{~J}$ coupling (one bond).

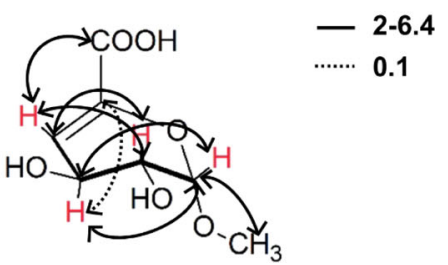

(g) $\mathrm{C}-\mathrm{H}$ heteronuclear ${ }^{3} \mathrm{~J}$ coupling (vicinal).
10-20 h), but no visible color is generated. This color formation commences as soon as the temperature is increased or the $\mathrm{pH}$ value decreased.

Primary degradation products of HexA: their stability, color and interrelation

It is known from literature that degradation of HexA can generate furan compounds, such as 5-formylfuran2-carboxylic acid (9) (Clavijo et al. 2012; Teleman et al. 1996). In this study, we were able to demonstrate that the three compounds 5-formylfuran-2-carboxylic acid (5-formyl-2-furoic acid, 9), furan-2-carboxylic acid (2-furoic acid, 10) and formic acid (11) were isolable intermediates of the HexA degradation. In addition, they are the only three compounds formed as initial degradation intermediates and they are obtained quantitatively under appropriately mild conditions: their masses add up to $100 \%$ of the starting material. In most previous studies these compounds had not been detected quantitatively as the degradation conditions were too severe so that these intermediates were almost intermediately consumed further. Treatment of 1 at $50{ }^{\circ} \mathrm{C}$ in weakly acidic medium $(\mathrm{pH}=4.5)$ generates a mixture of $\mathbf{9 , 1 0}$, and $\mathbf{1 1}$ after $19 \mathrm{~h}$ (see Fig. 1 and experimental section). Note that these conditions are different from just dissolving $\mathbf{1}$ in distilled water. A $10 \mathrm{mM}$ solution of $\mathbf{1}$ in distilled water (non-buffered) produces an immediate $\mathrm{pH}$ of 4.9 (note that $\mathbf{1}$ is a carboxylic acid) and the $\mathrm{pH}$ drops further due to degradation to a final $\mathrm{pH}$ of 3.6 after $5 \mathrm{~h}$ at $50{ }^{\circ} \mathrm{C}$. All three initial degradation products are 
Fig. 1 Degradation of HexA model compound 1 under mild conditions (0.1 M, $\left.50{ }^{\circ} \mathrm{C}, \mathrm{pH} 4.5\right)$ into a colorless mixture of 5-formyl-2-furoic acid (9), furan-2-carboxylic acid (2furoic acid, 10) and formic acid (11). Under harsher conditions, a brownish solution is furnished that quickly turns black and produces a black precipitate upon longer standing. (Color figure online)
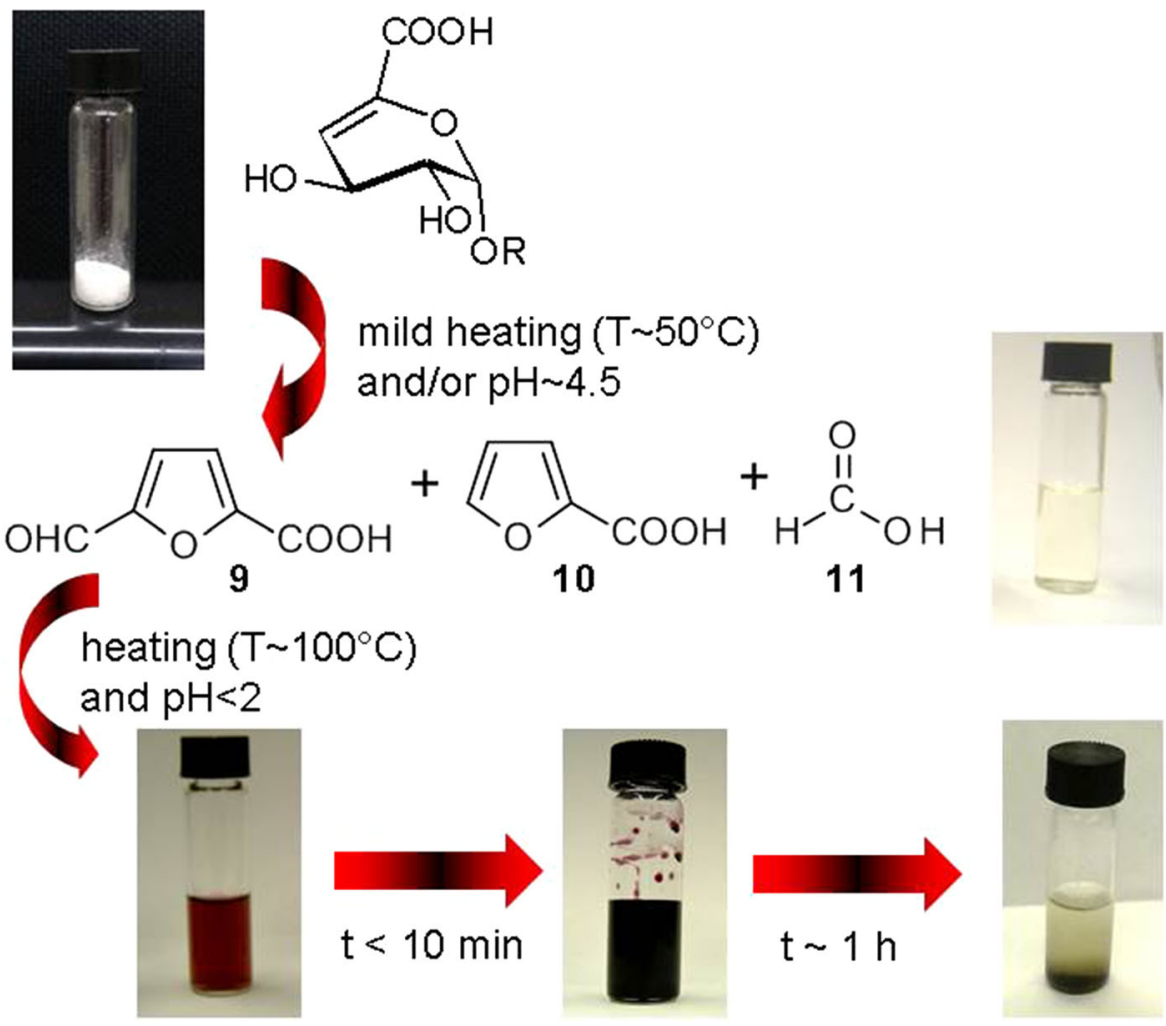

organic acids and are responsible for the drop in $\mathrm{pH}$ upon degradation of $\mathbf{1}$. At $50{ }^{\circ} \mathrm{C}$ and higher acidity ( $\mathrm{pH} 3$, phosphate buffer), consumption of $\mathbf{1}$ and degradation into 9, 10, and $\mathbf{1 1}$ was much faster and already complete after $23 \mathrm{~min}$.

It should be noted that the three initial degradation intermediates are not chromophores per se (as erroneously stated in many literature accounts). The same applies, by the way, also to similar furan compounds, such as furfural or hydroxymethylfurfural (HMF). That formic acid (11) is colorless is commonly known, but also 2-furoic acid (10) in pure form is a white solid (m.p. $\sim 130^{\circ} \mathrm{C}$ ), as is 5-formyl-2-furoic acid (9, m.p. $\sim 211^{\circ} \mathrm{C}$ ). However, both $\mathbf{9}$ and $\mathbf{1 0}$ are quite unstable towards oxygen (ambient air), acids, strong bases and heat, and so they rarely occur in pure form. If not freshly purified, they are accompanied by strongly colored degradation products, so that their appearance is usually yellowish to brownish. When kept standing at room temperature in air at a relative humidity of $60 \%$, both compounds generate byproducts, which is reflected by a constantly decreasing melting point, so that after some days an oil is obtained. An atmosphere containing some acetic acid vapor $(0.1 \mathrm{ml}$ of glacial acetic acid in a gas volume of 2 1) degrades both compounds completely to brownish oil within $8 \mathrm{~h}$, while hydrogen chloride vapor $(0.1 \mathrm{ml}$ of $1 \mathrm{M}$ aqueous $\mathrm{HCl}$ in a gas volume of $2 \mathrm{l}$ ) causes formation of a black tar already within 20 min.

It is thus certainly true that both 5-formyl-2-furoic acid (9) and 2-furoic acid (10) are potent chromogens (from Ancient Greek: $\chi \rho \omega \mu \alpha=$ color and $\gamma \varepsilon v \varepsilon \sigma \omega$ $1 \varsigma=$ origin, formation), i.e. they are able to produce chromophores, they are chromophore precursors. But neither of them is a chromophore itself (from Ancient Greek: $\chi \rho \omega \mu \alpha=$ color and $\phi \varepsilon \rho \varepsilon \mathrm{v} v=$ to carry). Formic acid (11), as the third HexA degradation product, is evidently neither a chromogen nor a chromophore.

Interestingly, when HexA model compound $\mathbf{1}$ was stressed under mild degradation conditions $\left(50{ }^{\circ} \mathrm{C}, \mathrm{pH}\right.$ 4-5), always the same molar amounts of 2-furoic acid (10) and formic acid (11) were formed, i.e., their ratio was always 1 . Moreover, the sum of 5-formyl-2-furoic acid (9) and 2-furoic acid (10) was constant, with 9 being slowly consumed and $\mathbf{1 0}$ being formed at the same rate. It was thus logical to assume that 9 was the precursor of both $\mathbf{1 0}$ and 11. Indeed, under the conditions of mild degradation of HexA model 
Fig. $2{ }^{1} \mathrm{H}$ NMR spectra of the slow conversion of 5-formyl-2-furoic acid (9, abbrev. FFA, top spectrum) into 2-furoic acid (10, abbrev. FCA) and formic acid (11, abbrev. FA) at $\mathrm{pH}$ 4. The reaction mixture was analyzed after different reaction times (approx. every $20 \mathrm{~min}$, middle spectra 2-5) with the approximate molar ratios given above the trace. The molar ratio of $\mathbf{1 0}$ and $\mathbf{1 1}$ was constant at 1:1 throughout, and the two compounds were the only products after complete consumption of 9 (bottom spectrum)

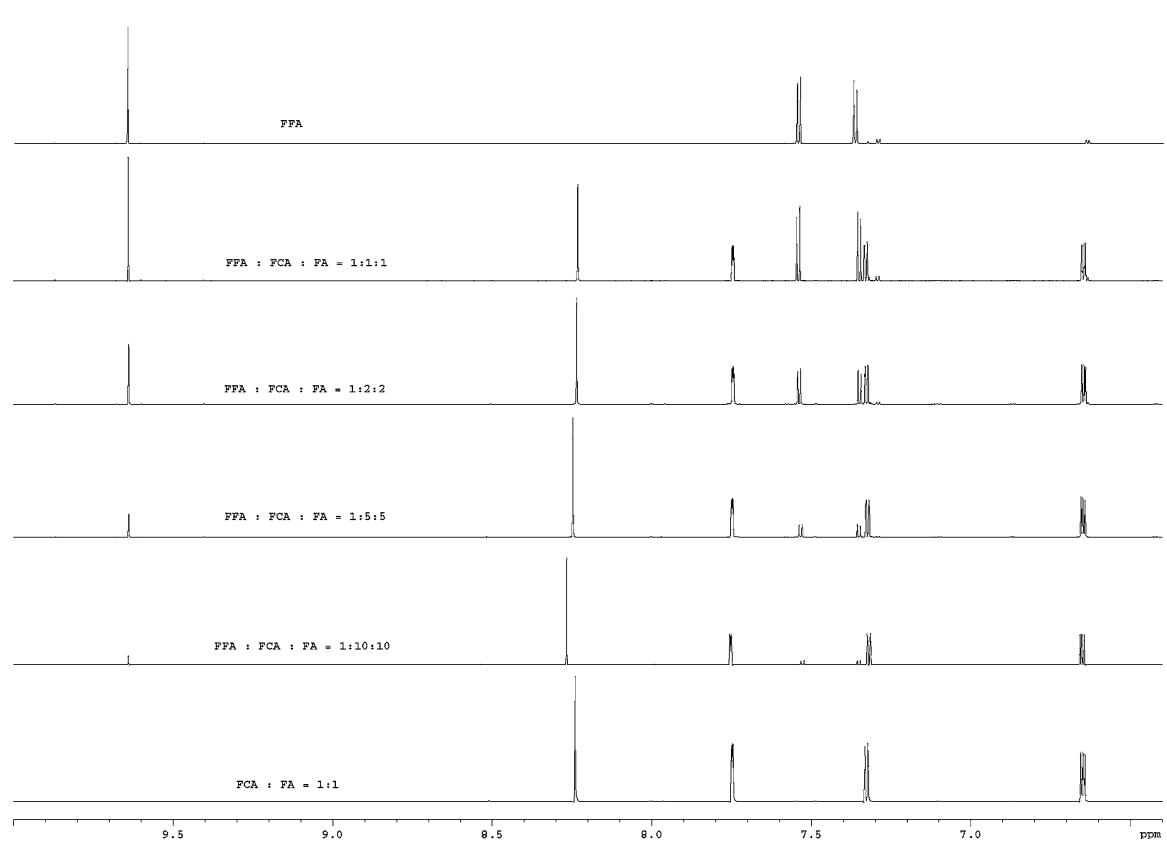

A detailed kinetic description (rate constants and Arrhenius activation energies) of the reaction system $\mathbf{1} \rightarrow \mathbf{9} \rightarrow \mathbf{1 0}+\mathbf{1 1}$ has not yet been performed since it did not seem crucial with regard to the main aim of chromophore identification and formation mechanisms. It was already evident, however, that the rate of the degradation of $\mathbf{1}$ was dependent on both the $\mathrm{pH}$ value (i.e. the proton concentration) and the model compound's concentration. The same was true for the consumption of $\mathbf{9}$. Therefore second-order kinetics appeared likely for both degradation processes, thus giving a system of coupled follow-up reactions with 9 playing the role of an intermediate whose stability (and thus stationary concentration) decreased with increasing acidity of the medium.

It is understood that the mild conditions are not relevant for industrial bleaching that is done at much more drastic settings, but they are necessary for mechanistic studies in order to get hold of the unstable furoic acid intermediates $\mathbf{9}$ and $\mathbf{1 0}$ (and the stable product $\mathbf{1 1}$ ).

Mechanism of formation of the primary HexA degradation products

The mechanism of formation of 5-formyl-2-furoic acid (9) from HexA units is readily understood (see Scheme 5). A furan moiety cannot be formed unless 


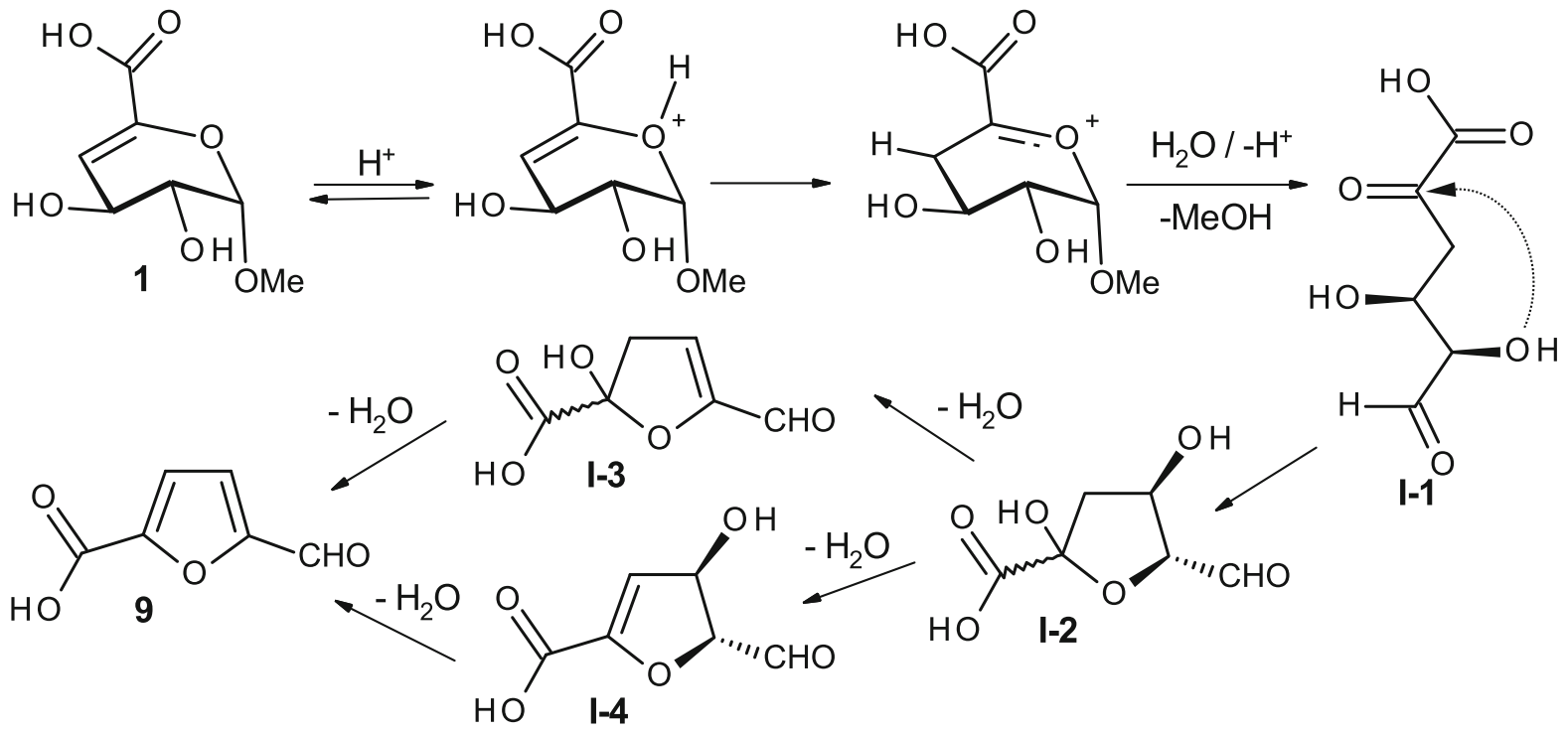

Scheme 5 Mechanism of formation of 5-formyl-2-furoic acid (9) from HexA model compound methyl 4-deoxy- $\beta$-L-threohex-4-enopyranosiduronic acid (1). Intermediates I-1 and I-2 were detectable by NMR spectroscopy with the help of

the six-membered ring in $\mathbf{1}$ is opened. This requires acidic media as $\mathbf{1}$ is quite stable in neutral and moderately alkaline medium (the degradation in strong alkali follows a different mechanism which cannot be discussed here). The first elementary step in the sequence is thus protonation of the ring oxygen as the most nucleophilic position with concomitant ring opening. This seems to be the rate determining step, which also explains the involvement of $\mathrm{H}^{+}$in the rate law (see above). The ring opening itself corresponds to the cleavage of the enol ether structure, for which generally two mechanisms are discussed that are distinguished by the order of the two elemental steps: either initial cleavage of the ether (the $\mathrm{C} 1-\mathrm{O} 5$ bond) followed by tautomerization of the enol to the ketone, or initial [1, 3]-sigmatropic proton shift (from the protonated ring oxygen to $\mathrm{C} 4$ ) with concomitant ether bond (C1-O5) cleavage. At the same time water is added to the anomeric carbon with loss of methanol from the resulting hemiacetal, producing the $\alpha$ ketoacid intermediate I-1 (Scheme 5). In an DMSO$\mathrm{d}_{6} / \mathrm{D}_{2} \mathrm{O}$ mixture $(\mathrm{v} / \mathrm{v}=3: 1)$, the open-chain form of $\mathbf{I}$ 1 can be detected, having a ${ }^{13} \mathrm{C}$ resonance at $205 \mathrm{ppm}$, albeit only in the case of the $5-{ }^{13} \mathrm{C}$-labeled starting material 1e with its "enforced" C5-sensitivity. In ${ }^{13} \mathrm{C}$ NMR experiments, the sensitivity of the labeled positions $\left(>99 \%{ }^{13} \mathrm{C}\right)$ is increased by a factor of about isotopically labeled starting material despite their low concentration, whereas intermediates $\mathbf{I}-\mathbf{3}$ and $\mathbf{I}-\mathbf{4}$ were too short-lived for such direct monitoring, even with ${ }^{13} \mathrm{C}$-labeled compounds

100 in comparison to the non-labeled compound with natural ${ }^{13} \mathrm{C}$ abundances throughout $(\sim 1 \%)$.

Hypothetical protonation at the glycosidic oxygen appears to play no role in the mechanism: in that case competitive nucleophiles present (fluoride, cyanide, diethyl malonate) should trap the intermediate C1cation by retention of the pyranose ring, which was not observed. Instead, all trapping products were ringopened, having an $\alpha$-keto structure similar to I-1.

The next step is the entropically driven formation of a furan ring $\mathbf{I - 2}$ by nucleophilic attack of the C2hydroxyl at the 5-keto carbon. By means of the ${ }^{13} \mathrm{C}$ labeled compounds, also this intermediate can be detected despite its very low concentration; characteristic resonances are $\mathrm{C} 1$ at $181.3 \mathrm{ppm}$ (seen when starting from C1-labeled compound 1a) and C5 at 95.4 ppm (seen when starting from C5-labeled compound 1e) in DMSO- $\mathrm{d}_{6} / \mathrm{D}_{2} \mathrm{O}(\mathrm{v} / \mathrm{v}=3: 1)$. From this intermediate, two eliminations of water, establishing the double bonds between $\mathrm{C} 2-\mathrm{C} 3$ and $\mathrm{C} 4-\mathrm{C} 5$, are required to form furan derivative 9 . These eliminations appeared to be very fast, and neither of the hypothetical intermediates $\mathbf{I}-\mathbf{3}$ and $\mathbf{I}-\mathbf{4}$ could be detected, not even at lower temperatures. When acidity and temperature were sufficient to induce ring opening of $\mathbf{1}$ and thus formation of the transient intermediates I-1/I$\mathbf{2}$, the subsequent processes leading to $\mathbf{9}$ were 

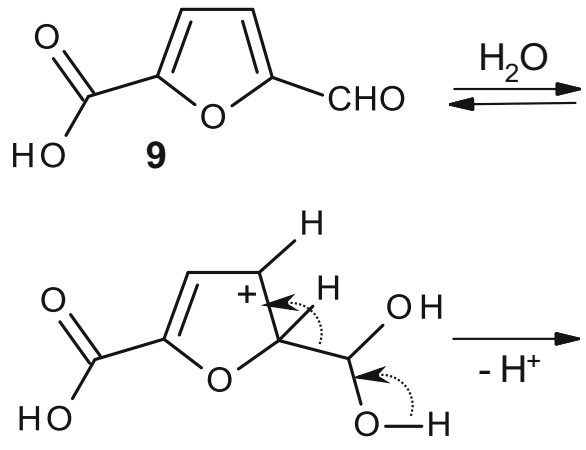

Scheme 6 Proposed mechanism of the loss of formic acid (11) from 5-formyl-2-furoic acid (9) under formation of 2-furoic acid (10). Note that-while the aldehyde hydrate $\mathbf{I - 5}$ is detectable in

apparently so much favored that they occurred "automatically".

A possible mechanism for the further conversion of 5-formyl-2-furoic acid (9) into 2-furoic acid (10) and formic acid (11) is shown in Scheme 6. The reaction is formally a deformylation (in general: deacylation) of the 2-furoic moiety, which usually does not occur; strongly acidic media would catalyze the reaction in principle, but this would rather cause degradation of the furan system than deacylation. A hint as to a possible mechanism was the fact that in strongly polar NMR solvents, such as DMAc/LiCl (Adelwoehrer et al. 2008) or ionic liquids, such as BMIM acetate (Yoneda et al. 2009), the formyl group in 9 was not only present as aldehyde $(-\mathrm{CHO})$, but also in the form of an aldehyde hydrate $\left(-\mathrm{CH}(\mathrm{OH})_{2}\right)$, if the solvent contained some water. In perdeuterated BMIM acetate containing $5 \%$ of $\mathrm{D}_{2} \mathrm{O}$, the ratio between aldehyde and aldehyde hydrate at $20{ }^{\circ} \mathrm{C}$ was $87: 13$, estimated from the ${ }^{13} \mathrm{C}$ resonances at $186.3 \mathrm{ppm}$ and $98.8 \mathrm{ppm}$, respectively. Assuming that the hydrate form would also be present in weakly acidic water medium to small extent (it was not detectable by NMR, however), a deformylation under temporary acid-catalyzed dearomatization of the furan followed by subsequent rearomatization is mechanistically plausible (see Scheme 6).

The furan system's weak aromaticity can be canceled relatively easily (Achmatowicz et al. 1971), so a dearomatization/rearomatization sequence would per se be conceivable. The fact that deformylation did not occur upon thermal treatment in water at neutral $\mathrm{pH}$, but required some weak acidity, might be seen as support for that mechanism. However, it cannot be
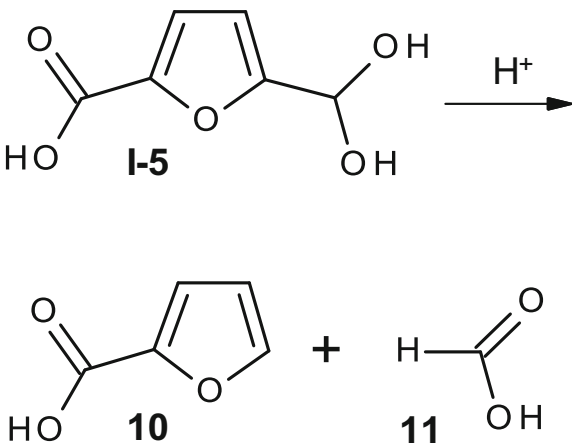

special solvents and the individual steps are in line with organic chemistry rules-the mechanism fails to explain why 9 undergoes deformylation, but other furfural derivatives do not

answered why 5-formyl-2-furoic acid (9) undergoes deformylation, but furfural and 5-hydroxymethylfurfural (HMF) do not, as is experimentally confirmed. It would be remarkable that the $\mathrm{COOH}$ group in 9 changes the reactivity of the furan moiety so profoundly and selectively that deformylation occurs, while it does not in the case of other substituents $(-\mathrm{H}$ in furfural or $-\mathrm{CH}_{2} \mathrm{OH}$ in $\mathrm{HMF}$ ). At present, only the neat deformylation of $\mathbf{9}$ in weakly acidic aqueous medium can be stated, but we are unable to offer a convincing mechanistic rationale for this process.

In context with the mechanistic considerations it should eventually be mentioned that reductic acid (2,3-dihydroxy-cyclopent-2-en-1-one) was not found as a primary degradation intermediate of HexA and only in negligibly small concentrations in later stages of HexA degradation (see next part of this series on the structure of the HexA-derived chromophores). The compound has been proposed to be an intermediate in the color formation of HexA (Sevastyanova et al. 2006a, b). We do not claim that reductic acid plays no role in the degradation chemistry of HexA, we were just unable to confirm its presence both in our model experiments under mild conditions and in HexA degradation experiments under more harsh conditions resembling industrial "A stages" or bleaching sequences.

\footnotetext{
${ }^{13} \mathrm{C}$ isotopomers of the primary degradation products and their NMR connectivities
}

The degradation of methyl 4-deoxy- $\beta$-L-threo-hex-4enopyranosiduronic acid (1) into 5-formyl-2-furoic acid (9) and further to 2-furoic acid (10), see 
Scheme 7 Structures of the

${ }^{13} \mathrm{C}$-isotopomers of

5-formyl-2-furoic acid (9a9f) and of 2-furoic acid (10b-10f) derived from the isotopically labeled HexA model compounds 1a-1f. Degradation of 9a provides non-labeled 10 and ${ }^{13} \mathrm{C}$ formic acid
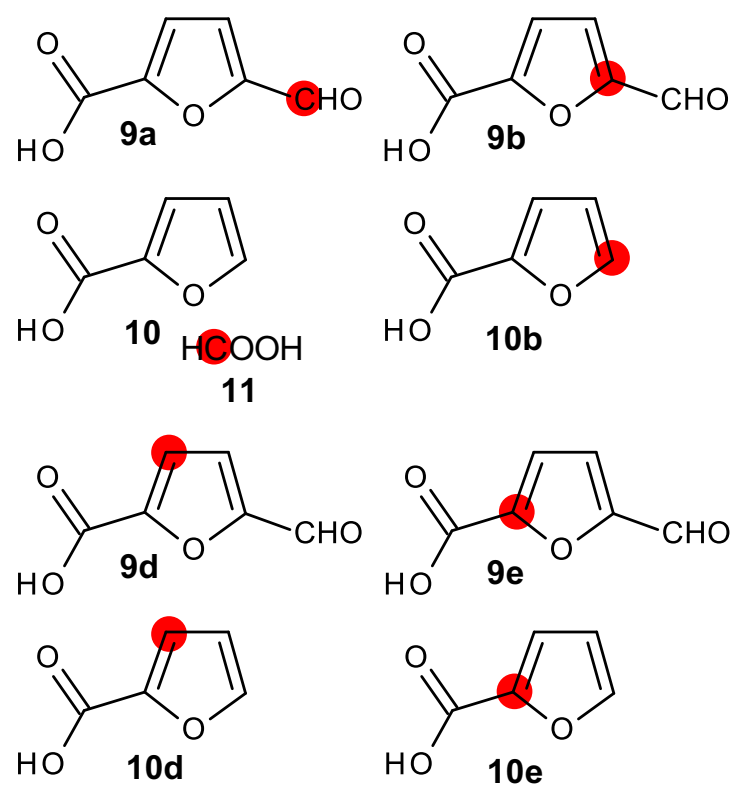
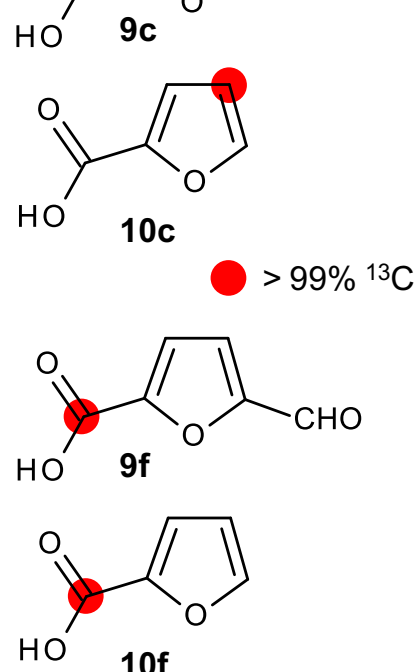

${ }^{2} J_{\mathrm{C}, \mathrm{C}}$ couplings were about $0.8 \mathrm{~Hz}$ throughout both

Scheme 6, was repeated six times, starting with the different ${ }^{13} \mathrm{C}$-isotopomers 1a-1f, which each had a ${ }^{13} \mathrm{C}$-monolabel at one of the six carbon atoms. This way, six different isotopomers of 5-formyl-2-furoic acid (9) and five isotopomers of 2-furoic acid (10) were obtained. In the case of 5-( ${ }^{13} \mathrm{C}$-formyl)-2-furoic acid (9a) the isotopic marker is "lost" in the form of ${ }^{13} \mathrm{C}$-formic acid (see experimental section). The structure of the compounds is given in Scheme 7, the position of the ${ }^{13} \mathrm{C}$-label being indicated again by a red dot.

Also for the furan compounds $\mathbf{9}$ and $\mathbf{1 0}$ a full description of the NMR spin systems was possible by means of the isotopically labeled specimens, including the chemical shifts and all homonuclear and heteronuclear couplings. The ${ }^{3} J$ homonuclear $\mathrm{H} 3-\mathrm{H} 4$ coupling was quite similar, around $3.5 \mathrm{~Hz}$, in both systems, the ${ }^{4} J$ coupling in $\mathbf{1 0}(\mathrm{H} 2-\mathrm{H} 4)$ being $0.8 \mathrm{~Hz}$. The direct homonuclear $\mathrm{C}, \mathrm{C}$ couplings within the furan system ranged between 49 and $72 \mathrm{~Hz}$, the coupling between $\mathrm{C} 3$ and $\mathrm{C} 4(\sim 49 \mathrm{~Hz})$ being smaller in both compounds by about $20 \mathrm{~Hz}$ than the other direct couplings in the ring system $(\sim 70 \mathrm{~Hz})$. Interestingly, the ${ }^{1} J_{\mathrm{C}, \mathrm{C}}$ coupling to the carbonyl carbons, which is usually about $90-100 \mathrm{~Hz}$, was $91 \mathrm{~Hz}$ and 96.2 for the carboxyl carbons in 9 and 10, respectively, but only $67.8 \mathrm{~Hz}$ for the $\mathrm{CHO}$ group in 9 . Whether this correlates with a special chemical behavior as indicated in Scheme 6 cannot be answered at the moment. furan systems and also to the exocyclic carbon substituents, and just significantly smaller than in the spin system of 1 (2.5-3.0 Hz in the ring). Interestingly, due to the five-membered ring structure, there are no "pure" ${ }^{3} J_{\mathrm{C}, \mathrm{C}}$ couplings in the spin systems, since they are always superimposed by another coupling over a different bond number, either as ${ }^{2,3} J_{\mathrm{C}, \mathrm{C}}$ or as ${ }^{3,4} J_{\mathrm{C}, \mathrm{C}}$. In simpler words, the coupling path between the furans' carbons can be "clockwise" or "counter-clockwise", and both contributions mix to the final value. The coupling of $\mathrm{C} 2$ with $\mathrm{C} 4$, for instance, is a ${ }^{2} J$ coupling via $\mathrm{C} 3$, and a ${ }^{3} J$ coupling via $\mathrm{O}$ and $\mathrm{C} 5$. All ${ }^{2,3} J_{\mathrm{C}, \mathrm{C}}$ and ${ }^{3,4} J_{\mathrm{C}, \mathrm{C}}$ values are in the range of $2 \mathrm{~Hz}$, with the exception of the couplings to the $\mathrm{COOH}$ group in 9 ( 0.8 and $1 \mathrm{~Hz}$, respectively). The only present ${ }^{4} J_{\mathrm{C}, \mathrm{C}}$ which would actually be a ${ }^{4,5} J_{\mathrm{C}, \mathrm{C}}$ value-is $0.3 \mathrm{~Hz}$, occurring between $\mathrm{CHO}$ and $\mathrm{COOH}$ in compound 9.

The direct heteronuclear couplings, i.e. ${ }^{1} J_{\mathrm{C}-\mathrm{H}}$, were all about $180 \mathrm{~Hz}$, both for the aromatic protons in the furan system and in the $\mathrm{CHO}$, with the exception of $\mathrm{C} 2$ in 10 with the rather high coupling of $205 \mathrm{~Hz}$. All of these carbons are $\mathrm{sp}^{2}$-hybrids. All longer-range couplings, i.e. ${ }^{2} J_{\mathrm{C}, \mathrm{H}}$ and ${ }^{3,4} J_{\mathrm{C}, \mathrm{H}}$, are in the expected range between 5 and $15 \mathrm{~Hz}$. Interestingly, while the carboxylic carbons in both $\mathbf{9}$ and $\mathbf{1 0}$ show a heteronuclear coupling with the furan protons, the $\mathrm{CHO}$ carbon in $\mathbf{9}$ does not, nor does the aldehyde proton connect to the ring carbons-a possible correlation of these NMR 
peculiarities with the special deformylation behavior once more being unknown.

\section{Conclusions}

Yellowing, bleaching and brightness reversion are evidently "big topics" in pulp and paper manufacturing, science of cellulosic materials in general, and conservation science, and it is also obvious that hexeneuronic acid is a potent contributor to bleaching, brightness and brightness reversion phenomena. At the same time, the topic is only relevant for wood starting materials and their mixtures, which contain D-glucuronoxylan, of which the 4-O-methylglucuronic acid residues are converted to HexA moieties during pulping. Still, hardwood pulps are frequently used, making the topic of HexA-derived chromophores not only scientifically challenging, but also economically highly important. From the studies applying the CRI method to isolate chromophores from cellulosic matrices in order to determine their structures we have learned that the concentration of individual chromophores is extremely low: in the low ppm to ppb range. Both the unambiguous confirmation of the chromophores' structures as well as kinetic or mechanistic studies required the synthesis of authentic samples. To link those structures with possible precursors-such as model compounds of oxidized anhydroglucose units in cellulose-was only possible by means of isotopic labeling with ${ }^{13} \mathrm{C}$-markers. Otherwise, the complexity of mechanisms and product mixtures overwhelm the analytical capabilities. With the instrument of labeling, the fate of particular carbons can be tracked along a process, and fragmentations or condensations/recombinations can be conveniently followed. It was logical to apply the same tool for similar mechanistic studies concerning HexA.

The synthesis of the HexA moiety (with a truncated xylan backbone mimicked by a methyl group) was straightforward, but required careful optimization of each step to boost yield and byproduct recovery to lose as little of the costly ${ }^{13} \mathrm{C}$-labeled starting material as possible. An approx. $45 \%$ overall yield over 7 steps was satisfying. The same sequence provided six ${ }^{13} \mathrm{C}$ isotopomers with labels at each of the respective six carbons (non-labeled compound $\mathbf{1}$ and isotopomers 1a-1f).

The HexA model compound is highly unstable at elevated temperatures $\left(\mathrm{T}>50{ }^{\circ} \mathrm{C}\right)$ and in acidic media
$(\mathrm{pH}<6)$. Removal of HexA residues in bleaching sequences is done in so-called "A stages", which work with acid at elevated temperatures (Chakar et al. 2000; Johansson and Samuelson 1977; Clavijo et al. 2012). Under those conditions, dark colored chromophores are very rapidly formed (seconds to few minutes) from HexA, and these processes are too fast for any detailed mechanistic or kinetic studies. Fortunately, reduced acidity and moderate temperatures $(\mathrm{pH} \sim 4.5$, $\mathrm{T}=50{ }^{\circ} \mathrm{C}$ ) slowed down HexA degradation in a way that chromophore formation was slowed down and even primary degradation intermediates could be captured. Under suitably mild conditions, HexA (1) degrades neatly into 2-formyl-furan-5-carboxylic acid (9), which -in a slightly slower process-is further degraded to furan-2-carboxylic acid (10) and formic acid (11). Kinetically, formation and consumption of 9 is described by a system of two consecutive reactions; conditions must be carefully controlled if higher amounts of 9 are to be isolated. At longer reaction times $\mathbf{9}$ will be consumed and only $\mathbf{1 0}$ is found (besides accompanying formic acid). The mechanism of the formation of 9 from HexA includes ring opening to an open-chain $\alpha$-ketoacid intermediate, which in turn undergoes ring closure to a furanose derivative. Both intermediates can be directly observed by NMR. Further double dehydration forms the furan product 9. Its subsequent conversion into $\mathbf{1 0}$ can be explained by a formally correct deformylation mechanism. However, it remains an open question why $\mathbf{1 0}$ would (relatively easily) undergo deformylation, but structurally quite similar compounds such as furfural or hydroxymethylfurfural do not. The neat conversion of $\mathbf{1}$ into a mixture of $\mathbf{9}$ and $\mathbf{1 0}$ allowed for the synthesis of these compounds also as respective ${ }^{13} \mathrm{C}$-isotopomers (9a-9f and $\mathbf{1 0 b}-\mathbf{1 0 f}$ ), starting from the respective labeled compounds 1a-1f.

With all these compounds at hand, it was now possible to address the topic of what the chemical structures of the HexA-derived chromophores would be and how they are formed. This will be the topic of the following part of this series.

Acknowledgments Open access funding provided by University of Natural Resources and Life Sciences Vienna (BOKU). The authors would like to acknowledge the financial support of the Austrian Christian Doppler Research Society (Christian-Doppler laboratory "Advanced cellulose chemistry and analysis") and the Austrian Forschungsförderungsgesellschaft (FFG) for financial support through project 847169 ("Chromophores II"). 
Open Access This article is distributed under the terms of the Creative Commons Attribution 4.0 International License (http:// creativecommons.org/licenses/by/4.0/), which permits unrestricted use, distribution, and reproduction in any medium, provided you give appropriate credit to the original author(s) and the source, provide a link to the Creative Commons license, and indicate if changes were made.

\section{References}

Achmatowicz A, Bukowski P, Szechner B, Zwierzchowska Z, Zamojski A (1971) Synthesis of methyl 2,3-dideoxy-DLalk-2-enopyranosides from furan compounds. General approach to the total synthesis of monosaccharides. Tetrahedron 27:1973-1996

Adelwoehrer C, Yoneda Y, Nakatsubo F, Rosenau T (2008) Synthesis of the perdeuterated cellulose solvents $\mathrm{N}$-methylmorpholine N-oxide (NMMO-d11) and $\mathrm{N}$, N-dimethylacetamide (DMAc-d9). J Label Compd Radiopharm 51(1):28-32

Adorjan I, Potthast A, Rosenau T, Sixta H, Kosma P (2005) Discoloration of cellulose solutions in $N$-methylmorpholine- $N$-oxide (Lyocell). Part 1: studies on model compounds and pulps. Cellulose 12(1):51-57

Adorjan I, Jääskeläinen A, Vuorinen T (2006) Synthesis and characterization of the hexenuronic acid model methyl 4 -deoxy- $\beta$-L-threo-hex-4-enopyranosiduronic acid. Carbohydr Res 341:2439-2443

Chakar FS, Allison L, Ragauskas AJ, McDonough TJ (2000) Influence of hexenuronic acids on US bleaching operations. Tappi J 83:62

Clavijo L, Cabrera MN, Kuitunen S, Liukko S, Rauhala T, Vuorinen T (2012) Changes in a eucalyptus kraft pulp during a mild acid treatment at high temperature. Papel 73:59-64

Clayton DW (1963) The alkaline degradation of some hardwood 4-O-methyl-D-glucuronoxylans. Svensk Papperstidn 66:115-124

Hoai PM, Tsunoi S, Ike M, Inui N, Tanaka M, Fujita M (2004) Dicarboxylic degradation products of nonylphenol polyethoxylates: synthesis and identification by gas chromatography-mass spectrometry using electron and chemical ionization modes. J Chromatogr A 1061(1):115-121

Johansson MH, Samuelson O (1977) Epimerization and degradation of 2-O-(4-O-methyl- $\alpha$-D-glucopyranosyluronic acid)-Dxylitol in alkaline medium. Carbohydr Res 54:295-299

Kalinowski H-O, Berger S, Braun S (1984) ${ }^{13}$ C-NMR-Spektroskopie. Georg Thieme Verlag Stuttgart, New York

Karplus M (1963) Vicinal proton coupling in nuclear magnetic resonance. J Am Chem Soc 85(18):2870-2871

Korntner P, Hosoya T, Dietz T, Eibinger K, Reiter H, Spitzbart M, Röder T, Borgards A, Kreiner W, Mahler AK, Winter H, French AD, Henniges U, Potthast A, Rosenau T (2015) Chromophores in lignin-free cellulosic materials belong to three compound classes. Chromophores in cellulosics, XII. Cellulose 22(2):1053-1062

Li J, Gellerstedt G (1997) The contribution to kappa number from hexeneuronic acid groups in pulp xylan. Carbohydr Res 302:213-218
Marquez BL, Gerwick WH, Williamson RT (2001) Survey of NMR experiments for the determination of $\mathrm{nJ}(\mathrm{C}, \mathrm{H})$ heteronuclear coupling constants in small molecules. Magn Reson Chem 39(9):499-530

Otonani N, Yosizawa Z (1987) Preparation of phenyl 4-deoxy$\alpha$ - and $\beta$-L-threo-hex-4-enopyranosiduronic acids and determination of the anomeric specificity of the $\Delta-4,5$ glycosiduronase induced from Flavobacterium heparinum with heparin and chondroitin sulfate. Carbohydr Res 159:25-36

Potthast A, Rosenau T, Sartori J, Sixta H, Kosma P (2002) Hydrolytic processes and condensation reactions in the cellulose solvent system $\mathrm{N}, \mathrm{N}$-dimethylacetamide/lithium chloride. Polymer 44(1):7-17

Potthast A, Rosenau T, Kosma P, Saariaho A-M, Vuorinen T (2005) On the nature of carbonyl groups in cellulosic pulps. Cellulose 12(1):43-50

Potthast A, Schiehser S, Rosenau T, Kostic M (2009) Oxidative modifications of cellulose in the periodate system-Reduction and beta-elimination reactions. Holzforschung 63(1):12-17

Rosenau T, Potthast A, Milacher W, Hofinger A, Kosma P (2004) Isolation and identification of residual chromophores in cellulosic materials. Polymer 45(19):64376443

Rosenau T, Potthast A, Milacher W, Adorjan I, Hofinger A, Kosma P (2005a) Discoloration of cellulose solutions in $\mathrm{N}$ methylmorpholine- $N$-oxide (Lyocell). Part 2: isolation and identification of chromophores. Cellulose 12(2):197-208

Rosenau T, Adorjan I, Potthast A, Kosma P (2005b) Isolation and identification of residual chromomophores in cellulosic materials. Macromol Symp 223(1):239-252

Rosenau T, Potthast A, Kosma P, Suess H-U, Nimmerfroh N (2007) Isolation and identification of residual chromophores from aged bleached pulp samples. Holzforschung 61(6):656-661

Rosenau T, Potthast A, Kosma P, Suess H-U, Nimmerfroh N (2008) Chromophores in aged hardwood pulp-their structure and degradation potential. Tappi J 1:24-30

Rosenau T, Potthast A, Krainz K, Yoneda Y, Dietz T, Shields ZPI, French AD (2011) Chromophores in cellulosics, VI. First isolation and identification of residual chromophores from aged cotton linters. Cellulose 18(6):1623-1633

Rosenau T, Potthast A, Krainz K, Hettegger H, Henniges U, Yoneda Y, Rohrer C, French AD (2014) Chromophores in cellulosics, XI: isolation and identification of residual chromophores from bacterial cellulose. Cellulose 21(4):2271-2283

Sevastyanova O, Li J, Gellerstedt G (2006a) On the reaction mechanism of the thermal yellowing of bleached chemical pulps. Nordic Pulp Pap Res J 21:188-192

Sevastyanova O, Li J, Gellerstedt G (2006b) Influence of various oxidizable structures on the brightness stability of fully bleached chemical pulps. Nordic Pulp Pap Res J 21:49-53

Severson ML, Maciel GE (1984) A molecular orbital study of the dihedral angle dependencies of vicinal carbon-carbon coupling constants. J Magn Reson 57(2):248-268

Shimizu K (1981) $\beta$-Elimination of 2- $O$-(4- $O$-methyl- $\alpha$-D-glucopyranosyluronic acid)-D-xylose with methylsulfinyl carbanion and hydrolysis of the hex-4-enopyranosiduronic linkage. Carbohydr Res 92:219-224 
Teleman A, Harjunpaa V, Tenkanen M, Buchert J, Hausalo T, Drakenberg T, Vuorinen $\mathrm{T}$ (1995) Characterization of 4-deoxy- $\beta$-L-threo-hex-4-enopyranosyluronic acid attached to xylan in pine kraft pulp and pulping liquor by carbon-13 and proton NMR spectrometry. Carbohydr Res 272:55-71

Teleman A, Hausalo T, Tenkanen M, Vuorinen T (1996) Identification of the acidic degradation products of hexenuronic acid and characterization of hexenuronic acid-substituted xylooligosaccharides by NMR spectroscopy. Carbohydr Res 280:197-208

Tot I, Krainz K, Potthast A, Suess H-U, Rosenau T (2008) Comparative synthesis studies t owards methyl and phenyl 4-deoxy- $\beta$-L-threo-hex-4-enopyranosiduronic acid as model compounds of hexenuronic acid moieties in hardwood pulps. Macromol Symp 262:182-189

Tot I, Müller Y, Werner C, Rosenau T, Potthast A (2009) A novel, mild and selective methylation of carboxyl groups in cellulosic pulps. Holzforschung 63(6):657-664

Yoneda Y, Ebner G, Takano T, Nakatsubo F, Potthast A, Rosenau T (2009) Synthesis of the perdeuterated cellulose solvents 1-ethyl-3-methylimidazolium acetate (EMIM-OAc- $\mathrm{d}_{14}$ ) and 1-butyl-3-methylimidazolium acetate (BMIM-OAc- $\mathrm{d}_{18}$ ) and of $2-{ }^{13} \mathrm{C}$-butyl-3-methylimidazolium acetate. J Label Compd Radiopharm 52(6):223-226 